\title{
To Respond or Not to Respond: Measures of the Output Gap in Theory and in Practice*
}

\author{
Guy Segal \\ Bank of Israel
}

\begin{abstract}
This paper analyzes the implications of responding to either the model-based New Keynesian output gap or to its estimates, and in particular, a Hodrick-Prescott-filtered output gap or a linearly detrended output gap. Responding to these estimates instead of to the "true" unobserved output gap generates longlasting business cycles and lower welfare. Furthermore, correlations between the estimates and the theoretical output gap depend on the stochastic structure of the shocks affecting the economy. In particular, productivity shocks generate a negative such correlation. Hence, the output gap estimates may provide poor guidance to monetary policy.
\end{abstract}

JEL Codes: E32, E52.

\section{Introduction}

Over the last two decades, monetary policy analysis has been conducted mainly within the framework of the New Keynesian (NK) model, both by central bankers and by academia. A key variable in the NK model is the output gap, which reflects inflationary pressures from the demand side and explains inflation dynamics - as reflected in the New Keynesian Phillips curve (NKPC). The output gap is defined as the deviation of actual from potential output. Assuming that the monopolistic distortion remains 1 potential output is

*I am greatly indebted to Zvi Hercowitz for his guidance and support. I am grateful to Alex Cukierman, Assaf Razin, John C. Williams, and Joseph Zeira for useful comments and discussions. I also thank Akiva Offenbacher, Alex Ilek, Eyal Argov, participants in the seminars in the Bank of Israel and in TelAviv University, and an anonymous referee for helpful comments. Author e-mail: guy.segal@boi.org.il.

${ }^{1}$ Distortion stemming from monopolistic power of firms may be eliminated by the fiscal authority by a subsidy to production. 
defined as output that prevails under flexible prices, while price markups are held constant at their steady-state values. As such, potential output is unobserved, and thus practical policy advice from the model requires the use of an estimate for potential output and output gap.

The various estimates for the output gap can be divided into univariate statistic methods (e.g., Hodrick-Prescott filter and detrended output methods), unobserved-components methods (e.g., Kalman filter), or the production function approach. In this paper we compare NK-model-based output gaps with their Hodrick-Prescott (HP) and linearly detrended output gap estimates, and we analyze the implications of responding to these estimates instead of responding to the "true" unobserved NK-model-based output gap. It should be noted that the different estimates of the output gap are both model and definition sensitive. However, the consensus is that (short term) potential output should be more volatile than traditional smoothed estimates of it, as potential output responds to real shocks in the economy (Justiniano and Primiceri 2008, Neiss and Nelson 2005, and Smets and Wouters 2003b).

We follow McCallum (2001) and choose an analytic rather than historical perspective. We conduct Monte Carlo simulations of an extension of the basic NK model introduced in Galí (2008), and derive the theoretical output gap as well as different estimates of it as endogenous variables, by calculating them within the model in "real time." Cúrdia et al. (2015) also calculate the Hodrick-Prescottfiltered output gap as an endogenous variable, by applying Christiano and Fitzgerald's (2003) approximation of ideal band-pass filters to Baxter and King's (1999) ideal HP-filtered output gap. The advantage of Cúrdia et al.'s calculation is that it does not dramatically augment the dimension of the model's state vector. We calculate the HP and linearly detrended output gap using their exact formulation. The advantage of our calculation is that it sheds light on the analysis of the formation of the HP-filtered series.

In the historical perspective the analysis uses actual data, and hence it is exposed to the problem of identifying the true shocks. Here, this problem is inexistent because the shocks are known. By choosing an analytic perspective, we can identify the effect of each "true" structural shock on the economy, and particularly on the output gaps, and conduct a normative analysis. 
We assume that the central bank (CB) sets the monetary interest rate using a Taylor rule which responds to an output gap estimate, rather than the true output gap, while actual inflation responds to the true unobserved output gap 2 We find that a response of the central bank to an estimate of the output gap -instead of to the "true" unobserved output gap - generates long-lasting business cycles as well as lower welfare. The business cycles are created by the fact that both the HP-filtered output and the linearly detrended output identify potential output by smoothing actual output series regardless of the source of the shock affecting the economy. Hence, they fail to identify the "true" potential output.

Furthermore, following a technology shock, these estimates provide completely misleading indicators of potential output. A positive technology shock raises both output and potential output, with the latter increasing by more, so that the New Keynesian output gap decreases. However, the estimates of the output gap translate the observed rise in output to a lower rise in potential output, and as a result the output gap estimates increase.

Consequently, the paper analytically explains the early literature, which focused on the technology shock/trend productivity as the main source for measurement error of the estimates of the output gap. Using an analytic perspective within the canonical New Keynesian model, McCallum (2001) assumes that a measurement error in the output gap estimate stems from the CB's ignorance of the effect of a technology shock on the output gap. He shows that when the CB responds to the output gap estimate, it leads to higher volatility in inflation, output, and interest rate than when the $\mathrm{CB}$ responds to the true output gap. Furthermore, as the CB's response to the estimate of the output gap increases, volatilities increase. Hence, McCallum (2001) concludes that the CB should not respond to an output gap estimate. Orphanides et al. (2000) choose a mixture of historical and

\footnotetext{
${ }^{2}$ Our assumption implies that the private sector has full information while the CB does not, as in Aoki (2003) and Svensson and Woodford (2004). The logic behind this assumption is that at the micro level, the single firm which sets its prices knows its own relevant information-for example, its current production and cost conditions - while the $\mathrm{CB}$ has only a macro estimate. An aggregation of all firms then implies a wider set of information about the macro state of the supply side than the information set held by the CB. Furthermore, as argued by Svensson and Woodford (2004), this assumption allows the implications of a partial information assumption to be tractable.
} 
analytic perspectives, using the Federal Reserve's model of the U.S. economy, and examine the implications of measurement error in the estimate of the output gap for the design of monetary policy. They show, similar to McCallum (2001), that when the measurement error is large, such as when there is a significant structural change in the economy, the response of the $\mathrm{CB}$ to the measure of the output gap should decrease, although not completely. A similar result is shown in Orphanides (2003) and Smets (2002), where the latter interprets this as an explanation for the small empirical output gap coefficients in the interest rate rules reported in the literature. The long duration of the business cycle following a response of the central bank to one of the output gap estimates tested in this paper is explained by the fact that these estimates are derived by smoothing historical output series. This smoothing gives rise to sluggishness in the estimates, in contrast to the rapidly responding, forward-looking nature of the New Keynesian output gap. The implications of responding to a linearly detrended output gap are found to be the most pronounced, given the higher weights attached to historical output far in the past, compared with the weights in the Hodrick-Prescott filter. We find that correlations between the output gap and its estimates are sensitive to the variances of the different shocks (cost-push, demand, and technology shocks), and that the different estimates may provide misleading guidance to monetary policy, as has been shown empirically (Adolfson et al. 2014; Coenen, Smets, and Vetlov 2008; Neiss and Nelson 2005).

Another finding is that the volatility of the New Keynesian output gap and its estimates depends on monetary policy. If the central bank responds to the New Keynesian output gap, the volatilities of the true output gap and its estimates are about the same. However, when the central bank responds to an output gap estimate, the volatility of the New Keynesian output gap rises dramatically, while the volatility of the estimate is only slightly higher than when the central bank responds to the true output gap. This results from the fact that the output gap estimates examined in the paper are a moving average of actual output with an irregular inertia.

Finally, we follow the welfare analysis in Orphanides et al. (2000), where the inflation coefficient in the CB's interest rate rule is fixed, and the output gap's coefficient is optimal. Similar to Orphanides et al. (2000), we find that the optimal output gap coefficients exhibit 
attenuation, that is, the coefficients are small, although not zero. However, the price of responding to an output gap measure is higher output volatility. Like Orphanides et al. (2000), we also test the welfare implications of the CB's response to output growth rather than to output gap measure. We find that while responding to output growth is welfare improving in terms of the welfare function, it also leads to higher output volatility than in the alternative optimal rules, and hence it is preferable for the CB not to respond to output growth either.

The paper is organized as follows. Section 2 surveys the literature of the various definitions used for output gap within the NK model. Section 3 summarizes the NK model. Section 4 describes the calibration of the model. Section 5 analyzes the dynamic impulse response function and Monte Carlo simulations of the price markup shock, technology shock, and demand shock separately. Section 6 compares the output gap measures based on Monte Carlo simulations when all three shocks simultaneously hit the economy. Section 7 examines the welfare implications of responding to the various output gaps or to the output growth, and section 8 concludes.

\section{Literature Review of Output Gap Definitions}

In this section we summarize the various definitions used for the output gap in the New Keynesian framework. In this framework the output gap reflects inflationary pressures from the demand side and explains inflation dynamics.

As we assume that the monopolistic distortion is not offset by a subsidy and remains, we follow Adolfson et al. (2014), Sala, Söderström, and Trigari (2010), Smets and Wouters (2003a, 2003b), and Woodford (2003), and define potential output as that prevailing under flexible prices (and wages 3 ), while price (and wage) markups are held constant at their steady-state values. Hence, potential output is an unobserved variable. Smets and Wouters (2003b) show that the above potential output definition 4 narrows the gap between

\footnotetext{
${ }^{3}$ For simplicity, the model used here does not include wage markups.

${ }^{4}$ There is no definite consensus regarding the different output gap definitions. Different papers may use different notions for the same definitions mentioned in the literature review.
} 
traditional measures of the output gap and the model-based definition in comparison with natural output, in terms of volatility. They do, however, mention that potential output remains quite different from the traditional measures of the output gap.

Two other frequently used definitions in the NK framework are natural output and efficient output. Both, as well as the above definition of the potential output, relate to theoretical outputs when prices are flexible. The difference is that natural output (appendix 1) also responds to markup shocks, and it is relevant when the monopolistic distortion is eliminated. Efficient output (appendix 1) assumes perfect competition, and hence it is the relevant notion for welfare analysis.

Like Blanchard and Galí (2007) and Justiniano and Primiceri (2008), we derive analytically both potential and efficient modelbased outputs. We show that natural output cannot be higher than efficient output, and that the gap between the two is a function of the changes in the monopolistic power of the firms (section 7 ). In contrast to Justiniano and Primiceri (2008), efficient output in our model is higher than potential output by a constant, as in Adolfson et al. (2014) and Sala, Söderström, and Trigari (2010). While this outcome is similar to Blanchard and Galí (2007), it stems from different assumptions and definitions. Blanchard and Galí assume constant demand elasticity and use natural output (as we define it) as efficient output, while we assume stochastic demand elasticity.

We find that the economy is sensitive to monetary policy response to different output gaps, a finding that is in line with Adolfson et al. (2014). They show that different output gaps (detrended or potential output gaps) in the central bank objective function imply different transmission mechanisms in the economy. Specifically, they show that when the theoretical output gap enters the objective function, the trade-off between stabilizing inflation and stabilizing output is lower than when it is the traditional estimate of potential output gap which enters the loss function. However, while Adolfson et al. (2014) use an ad hoc welfare loss function and a historical perspective, we use Galí's (2008) model-based welfare loss function and an analytical perspective to evaluate the welfare implications of responding to different estimates of the output gap. The model-based welfare loss function includes a negative linear term on the efficient output gap, apart from the squared deviations of 
inflation and efficient output gap from steady state. This negative term reflects the positive effect of an increase in output on welfareas output is below its efficient level due to the monopolistic power of the firms. In sections 3-6 we focus on the output deviation from potential output, referring to it as output gap.

\section{The New Keynesian Model and Model-Based Output Gaps}

We use an extension of the basic NK model introduced in Galí (2008, ch. 3 and 5), where we assume the following: (i) A stochastic demand elasticity which reflects price markup shocks (following Adolfson et al. 2014, Christoffel, Coenen, and Warne 2008, Sala, Söderström, and Trigari 2010, and Smets and Wouters 2003a). In order to analyze monetary policy, a key feature of the model has to be the Taylor frontier - that is, the trade-off between inflation stabilization and output (gap) stabilization. As Clarida, Galí, and Gertler (1999) and Woodford (2003) show, the Taylor frontier may be introduced by including a shock to the Phillips curve. The stochastic demand elasticity reflects price markup shocks and induces the Taylor frontier. A decrease in the elasticity of demand implies an increase in market power of the monopolistic firms which raise prices. As prices rise, monetary interest rate is increased and output (gap) decreases. (ii) A preference shock to consumption in the utility function of the household, which reflects demand shocks (e.g., Cristoffel, Coenen, and Warne 2008 and Smets and Wouters 2003a).

\subsection{The Model's Main Structural Equations}

The model's two main structural log-linear equations are as follows (see appendix 1 for derivation):

$$
\begin{gathered}
\pi_{t}=\beta E_{t}\left\{\pi_{t+1}\right\}+\kappa \tilde{y}_{t}+\lambda \hat{\varphi}_{t}, \\
\tilde{y}_{t}=E_{t}\left(\tilde{y}_{t+1}\right)-\frac{1}{\sigma}\left(i_{t}-E_{t}\left(\pi_{t+1}\right)-r_{t}^{p}\right)+\frac{1}{\sigma}\left(1-\rho^{c}\right) \xi_{t} .
\end{gathered}
$$

Equation (1) is the NK Phillips curve (NKPC) derived from firms' optimal price setting à la Calvo. $\pi_{t} \equiv p_{t}-p_{t-1}$ is the inflation rate; $\tilde{y}_{t} \equiv y_{t}-y_{t}^{p}$ is the potential output gap - that is, the gap 
between output, $y_{t}$, and potential output, $y_{t}^{p}$, which is the output that would prevail in a flexible price economy when price markup shocks are held constant at steady-state values. Note that the potential output gap is not a deviation of output from its steady state. The potential output gap reflects inflationary pressures from the demand side. Potential output increases with positive consumption preference shocks and positive technology shocks but decreases as real distortion, stemming from the economy's monopolistic structure, increases (see appendix 1 for derivation). $\hat{\varphi}$ is the log-deviation of a markup shock from its steady state, which is assumed to follow an AR(1) process, $\hat{\varphi}_{t}=\rho^{\varphi} \hat{\varphi}_{t-1}+v_{t}^{\varphi}$, where $v_{t}^{\varphi}$ is white noise. $\beta$ is the discount factor, and $\kappa$ and $\lambda$ are structural parameters. Small letters denote the $\log$ of a variable, $\wedge$ denotes the log-deviation of a variable from steady state, and the operator $E_{t}$ denotes the mathematical unconditional expectation.

Equation (2) is the dynamic IS equation, which is derived from optimal consumer allocation (the Euler equation). $i_{t}$ is the nominal interest rate and $r_{t}^{p}$ is the potential real interest rate (see appendix 1 for derivation). $\xi_{t}$ is a consumption preference shock, a demand shock, which follows an AR(1) process $\xi_{t}=\rho^{\xi} \xi_{t-1}+v_{t}^{\xi}$, where $v_{t}^{\xi}$ is white noise. $\sigma$ is the inverse of the consumption intertemporal elasticity of substitution.

\subsection{Monetary Policy}

In order to close the model, we assume that the central bank (CB) uses a standard Taylor rule to set the monetary policy rate:

$$
i_{t}=\rho+\mu_{\pi} \cdot \pi_{t}+\mu_{x} \cdot g a p_{t}
$$

Although the Taylor rule is not a structural equation, in contrast to the NKPC and the IS equations (equations (11) and (2)), it is the most commonly used rule to model monetary policy. $\mu_{\pi}$ and $\mu_{x}$ are the Taylor-rule parameters and are set at the standard values $\mu_{\pi}=1.5$ and $\mu_{x}=0.5 / 4$ (Taylor 1993). As potential output is unobserved, we calculate within the model the HP-filtered output gap (HPG) and the linearly detrended output gap (LTG), which are computed using the simulated output, $y_{t}$, in real time 
(appendix 3)5:6 Finally, we assume that the steady state of the potential interest rate, $\rho$, is known.

To analyze the implication of the Taylor rule responding to an output gap estimate instead of the "true" output gap, we compare four variants of the model, which differ by the CB policy rule: (i) a Taylor rule which responds to the "true" potential output gap and is denoted by NKTR (New Keynesian gap Taylor rule), (ii) a Taylor rule which responds to the Hodrick-Prescott-filtered output gap (HPG), denoted by HPTR, (iii) a Taylor rule which responds to a linearly detrended output gap (LTG), denoted by LTTR, and (iv) a Taylor rule which responds only to inflation, denoted by SITR (strict inflation Taylor rule). The welfare analysis (section 7) also compares the implication of responding to output growth rather than to an estimate of output gap, a Taylor rule denoted by GTR (growth Taylor rule).

\section{Calibration}

Most parameters are calibrated based on Galí (2008, p. 52) (see table 1).

As for the markup shocks, in a basic model with exogenous costpush shock, Galí (2008) calibrates the autoregressive coefficient of the cost-push shock $\rho^{\varphi}=0.5$, while Sala, Söderström, and Trigari (2010) obtain the same value using U.S. data. Christoffel, Coenen, and Warne $(2008)$ estimate $\rho^{\varphi}$ in the range $(0.255,0.554)$ using European data, while Rabanal and Rubio-Ramírez (2008) estimate $\rho^{\varphi}=0.97$ using U.S. data. In line with Christoffel, Coenen, and Warne (2008), we set $\rho^{\varphi}=0.3$, as it yields a response similar to the estimated impulse response of inflation to a markup shock, as in Argov et al. (2012) and Christoffel, Coenen, and Warne (2008).

\footnotetext{
${ }^{5}$ Cúrdia et al. (2015) find that estimating a DSGE model with a Taylor rule, in which the HP-filtered output gap replaces the theoretical output gap, significantly improves the fit of the model to U.S. data. However, the main result of Cúrdia et al. (2015) is that including the efficient interest rate as the indicator of real activity in the policy rule fits the U.S. data better than alternative indicators do.

${ }^{6}$ The output trends are based on the last forty observations of simulated output (ten years' history).
} 
Table 1. Calibrated Parameters

\begin{tabular}{|l|c|l|}
\hline Parameter & Value & \multicolumn{1}{c|}{ Description } \\
\hline$\alpha$ & $1 / 3$ & Output elasticity with respect to labor \\
$\beta$ & 0.99 & Discount factor \\
$\varepsilon$ & 6 & Elasticity of substitution among goods \\
$\eta$ & 1 & Frisch elasticity of labor supply \\
$\theta$ & $2 / 3$ & Calvo price parameter \\
$\mu_{\pi}$ & 1.5 & Taylor-rule coefficient of inflation \\
$\mu_{x}$ & $0.5 / 4$ & Taylor-rule coefficient of output gap \\
$\sigma$ & 1 & Consumption intertemporal elasticity of \\
& & substitution (inverse) \\
$\rho^{a}$ & 0.9 & Persistence of technology process \\
$\rho^{\varphi}$ & 0.3 & Persistence of price markup process \\
$\rho^{\xi}$ & 0.85 & Persistence of consumption preferences \\
& & shock process \\
$\sigma^{a}$ & 0.03 & Standard deviation of technology process \\
$\sigma^{\varphi}$ & 0.0152 & Standard deviation of price markup process \\
$\sigma^{\xi}$ & 0.03 & Standard deviation of consumption \\
& & preferences shock process \\
\hline
\end{tabular}

As for the demand shocks, we set the autoregressive coefficient at $\rho^{\xi}=0.85$, following Rabanal and Rubio-Ramírez (2008) and Smets and Wouters (2003a).

We set the standard deviations of the shocks as follows. A standard calibration of a 20 percent price markup in steady state implies $\hat{\varphi}_{t} \in(-0.182, \infty)$ (section 7$)$. Assuming normal distribution, $\bar{\sigma}^{\varphi}=0.182 / 3=0.061$ is the upper limit of $\sigma^{\varphi}$ (with a probability of 99.7 percent). Finally, we calibrate $\sigma^{a}=\sigma^{\xi}=0.5 \bar{\sigma}^{\varphi}$ and $\sigma^{\varphi}=0.0152 \approx \bar{\sigma}^{\varphi} / 4$, as this calibration yields plausible simulated measures of the output gaps (section 5).

\section{Impulse Response Functions}

In this section we analyze the impulse response functions to a positive price markup, technology and demand shocks, which are later used for simulated data.

\subsection{Price Markup Shock-NKPC Shock}

A positive shock to the NKPC reflects a higher monopolistic power that stems from a decrease in the elasticity of substitution among 
differentiated goods. We normalize the markup shock in the NKPC and denote it by $u_{t} \equiv \lambda \hat{\varphi}_{t}$.

If the central bank responds either to the "true" output gap (NKTR) or only to inflation (SITR), the impulse response functions to a markup shock are standard (figure 1). A positive markup shock leads to a higher inflation rate $(\pi)$, while potential output $\left(y^{p}\right)$ and potential real interest rate $\left(r^{p}\right)$, by definition, do not change. Hence, in the presence of markup shocks only, potential output gap (output gap onwards) equals output. Inflation increases by more than the markup shock through the rational expectations channel-the expected increase in next-period inflation increases inflation today. To offset the markup shock, the interest rate $(i)$ is increased and output $(y)$ decreases roughly by 50 percent more than inflation. Thus, a trade-off between stabilizing inflation and stabilizing output gap emerges with a markup shock, reflecting the Taylor frontier. As the markup shock fades according to its data-generating process, the economy converges back to steady state in about six quarters.

Note that when the central bank responds either to the "true" output gap (NKTR) or only to inflation (SITR), but the econometrician detrends output using the HP filter or a linear trend, both estimates of the output gap reflect the Taylor frontier in the first two quarters but show a false hump-shaped evolution of the gap afterwards. This is in line with Harvey and Jaeger (1993), who show that an HP-filter detrending may lead to spurious business cycles.

If instead the central bank itself responds to the HodrickPrescott-filtered output gap (HPG), the impulse response function (IRF) to the markup shock is similar to the IRFs analyzed above, but with two major differences: (i) The response of the CB to the HPG "contaminates" actual output, $y$, and as a result the potential output gap (POG) is also "contaminated," that is, the hump-shaped evolution in the economy is now a real one. (ii) As a result, steady state is reached only after fifty periods (figure 2) 7 Figure 2 differs from figure 1 only in tracing the longer-run response 8

\footnotetext{
${ }^{7}$ While the long duration of the convergence to steady state implied by the IRF may look unreasonable at first glance, its plausibility may be tested only by simulating all shocks simultaneously as in reality (section 4 ). Indeed, the simulated smoothed output gap estimates in that case resemble actual output gap estimates.

${ }^{8}$ We drop variables $\pi, i, y^{p}, r^{p}$, and $u$ from figure 2 , as they converge rapidly to steady state.
} 

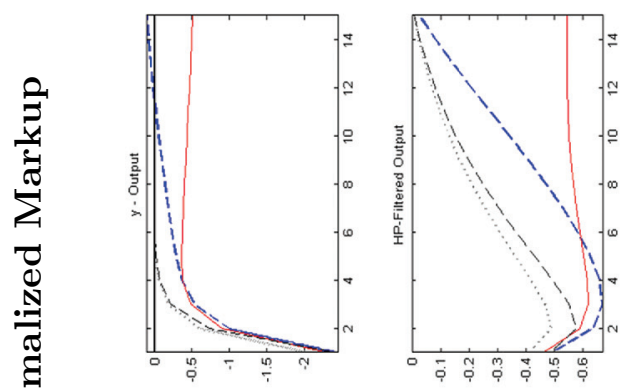

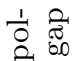

总

.

त्रे

节

表红

范

ซี่
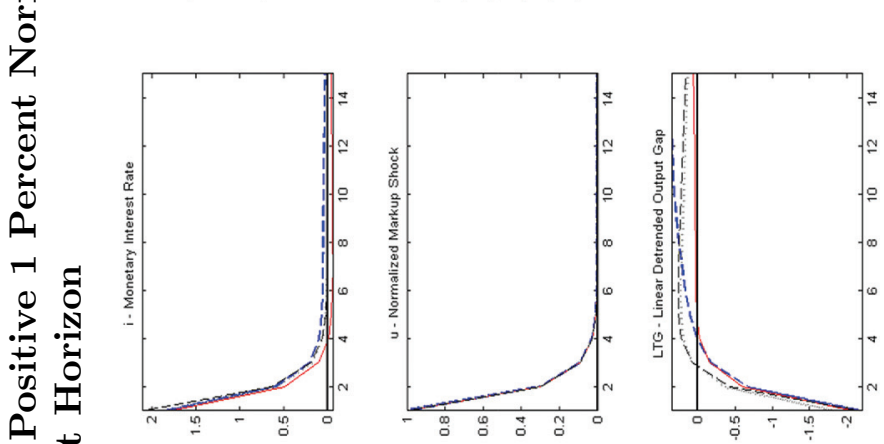

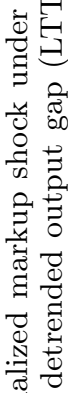
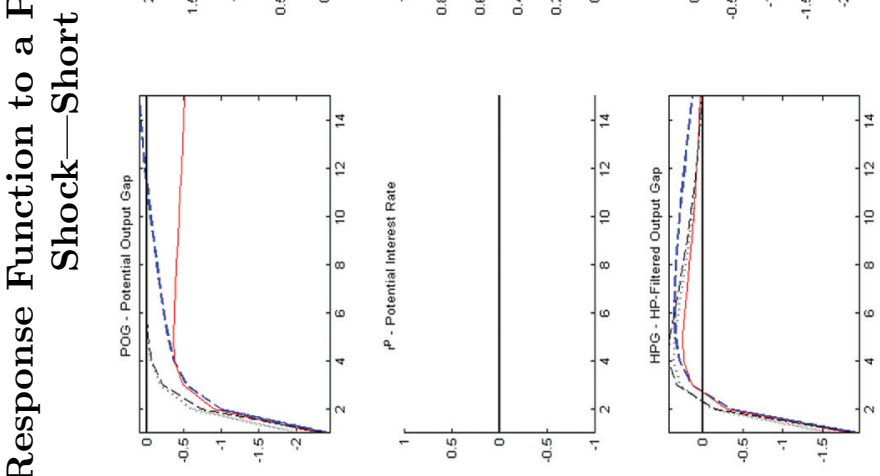

둥

르미

论

唲

보

: 웅

$\stackrel{2}{\circ}$,

๙

$\circ$ 壱。

응ㅁㅇ
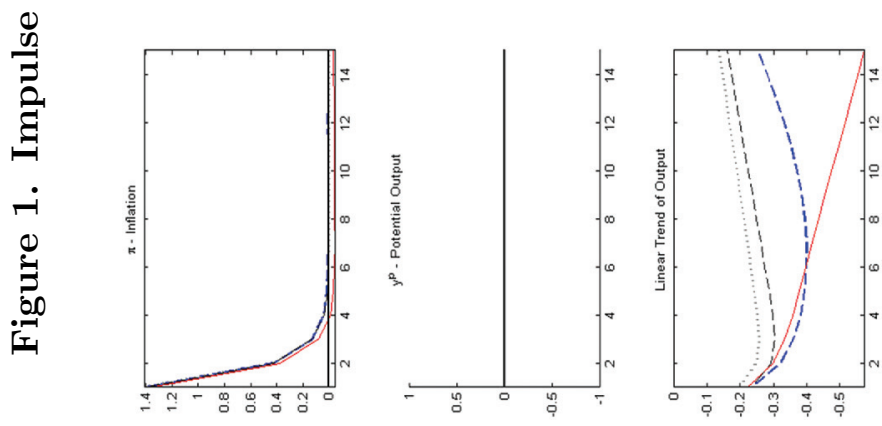

范 $\Xi$

壳

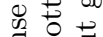

귱

कै

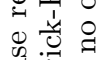

节矛

코엉

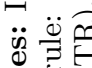

㩆 

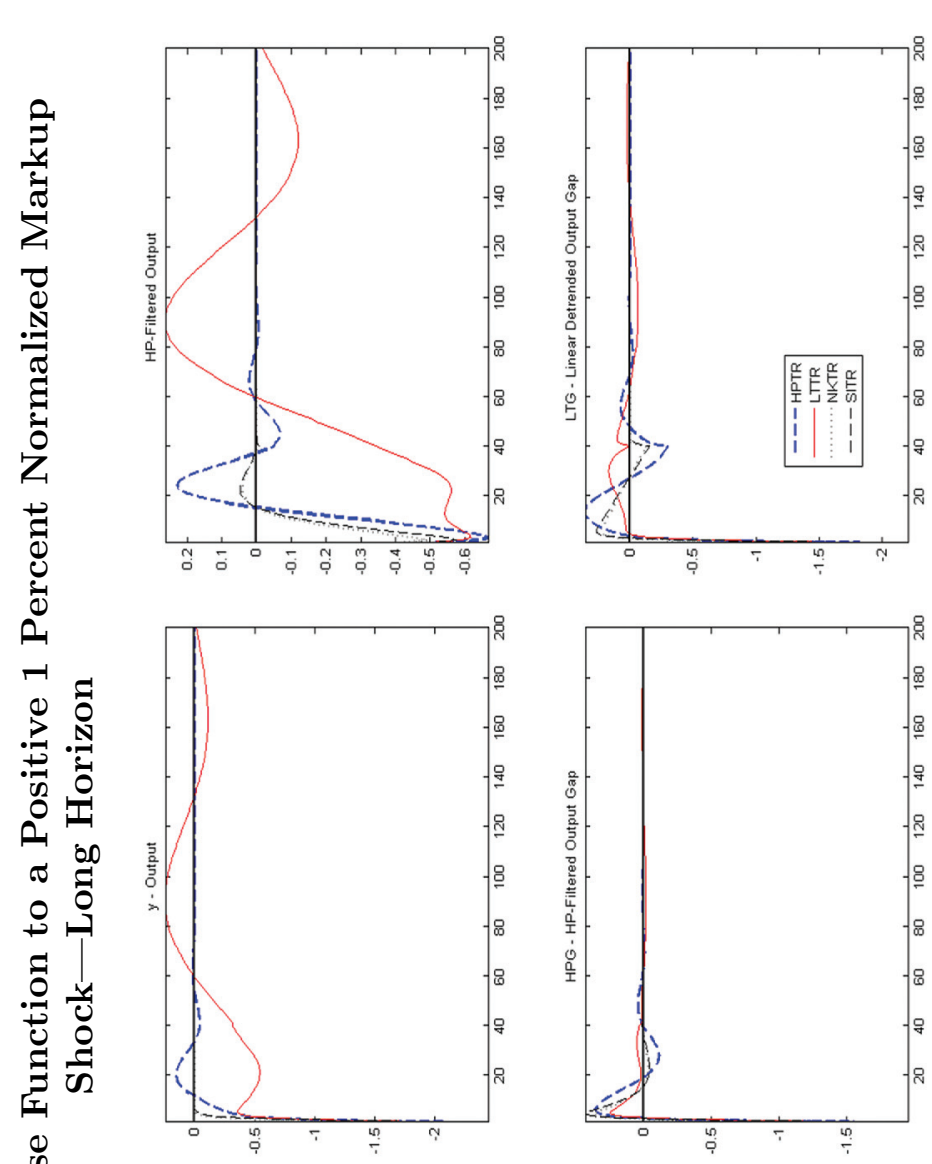

它

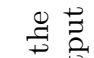
. 究. శี है 要, 学范 菅 苞兒 군

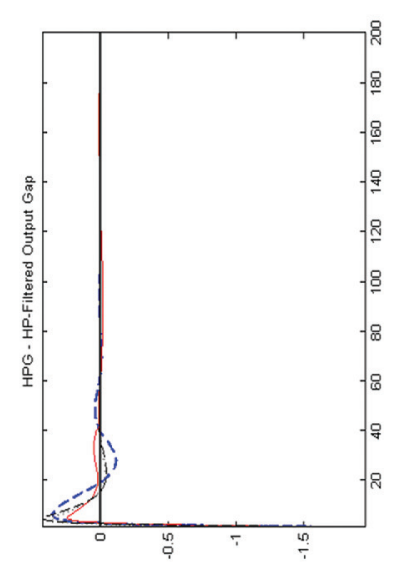
녹 节

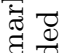
द्व 疋 สี घี

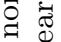
ㅂ. ․․ 楁 包 Q

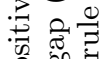
$\therefore$

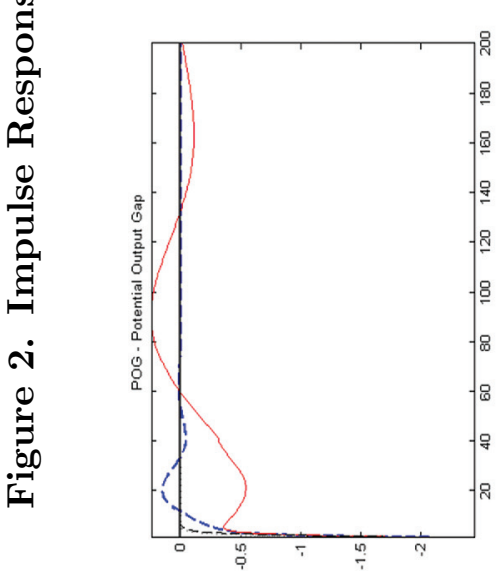

\% $\circ \stackrel{2}{\circ}$ 훙 o. $\exists$ 㐘 우 我 号 용 可 究 늘

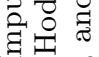

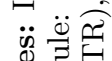
㩆暴 
The implications of responding to the linearly detrended output gap (LTG) after a markup shock are striking (LTTR); output remains under its steady state for about seventy quarters (figure 2). The response to the LTG creates a business cycle which is four times longer than the business cycle created after responding to the HPG; POG and output does not converge to steady state even after 200 quarters.

The business cycles created by a response to either HPG or LTG are explained by the fact that both estimates fail to identify the "true" output gap. These estimates smooth actual output series in a way that creates an artificial inertia in the estimated output gap. The poor indicative power of the Hodrick-Prescott-filtered output and the linearly detrended output results from (i) the statistical nature of these estimates and (ii) the fact that both estimates have no economic link to the definition of the New Keynesian output gap, as these estimates do not use any information other than actual output. As both HPG and LTG are based on a weighted historical average of output (of forty observations in the simulations), their convergence is therefore a slow one. The longer business cycle under LTTR in comparison with HPTR is explained by the smoother weights attached to historical outputs in the calculation of LTG9

\subsection{Understanding the Source of the Created Business Cycles}

In order to understand how these business cycles are created, we analyze the IRF presented above (markup shock only) and concentrate on the dynamic IS equation, the Phillips curve, and the policy rule:

$$
\begin{gathered}
\hat{x}_{t}=E_{t}\left\{\hat{x}_{t+1}\right\}-\frac{1}{\sigma}\left(i_{t}-E_{t}\left\{\pi_{t+1}\right\}-\rho\right), \\
\pi_{t}=\beta E_{t}\left\{\pi_{t+1}\right\}+\kappa \hat{x}_{t}+\lambda \hat{\varphi}_{t}, \\
i_{t}=\rho+\mu_{\pi} \cdot \pi_{t}+\mu_{x} \cdot \operatorname{gap}_{t} .
\end{gathered}
$$

We denote gap $_{t} \equiv y_{t}-\bar{y}_{t}$ as the measure of the output gap, where $\bar{y}_{t}$ is either the linear trend of output or its HP-filtered trend. $\bar{y}_{t}$ is

\footnotetext{
${ }^{9}$ We do not deal with the well-known endpoint bias of the HP-filtered output trend.
} 
a function of the sample size used for the calculation of the output trend, $T$ (equal to forty quarters in the simulations), and the historical output series. Specifically, the estimated endpoint of the output trend is calculated as $\bar{y}_{t}=\sum_{i=0}^{T-1} \chi_{i} y_{t-i}$, where $y$ is the output upto-date series in the last $T$ periods and $\chi_{i}$ is derived from the firstorder conditions of smoothing the target series (appendix 3). Note that $\chi_{i}$ has different signs for different $i$ 's. For the Hodrick-Prescott trend, with $T=$ forty quarters, $\chi_{i}$ is positive for $i=0,1, \ldots, 14$ and $i=37,38,39$ and negative for the rest of the $i$ 's. Plugging the policy rule, the Phillips curve, and the output trend expression into the dynamic IS equation yields the next expression for the output gap:

$$
\begin{aligned}
\hat{x}_{t}= & \left(1+\frac{\mu_{x}}{\sigma}-\frac{\kappa}{\beta \sigma}-\frac{\mu_{x}}{\sigma} \chi_{0}\right)^{-1} \\
& \times\left[E_{t}\left\{\hat{x}_{t+1}\right\}+\frac{1}{\beta \sigma}\left(1+\beta \mu_{\pi}\right) \pi_{t}-\frac{\lambda}{\beta \sigma} \varphi_{t}-\frac{\mu_{x}}{\sigma} \sum_{i=1}^{T-1} \chi_{i} y_{t-i}\right] .
\end{aligned}
$$

Note that when the CB responds to the "true" output gap, which in the case of only markup shock equals output, then $\chi_{i}=0 \forall i=$ $0,1,2, \ldots, T-1$. According to equation (44), when the CB responds to the "true" output gap, the output gap is linked to its expectations, the rate of inflation, and the markup shock. When instead the CB responds to the deviation of the output from a trend $\bar{y}_{t}$, then the output gap is also a function of a weighted average of the last $T$ observations of output, captured by the last term in equation (4) 10

$$
\left(1+\frac{\mu_{x}}{\sigma}-\frac{\kappa}{\beta \sigma}-\frac{\mu_{x}}{\sigma} \chi_{0}\right)^{-1}\left[-\frac{\mu_{x}}{\sigma} \sum_{i=1}^{T-1} \chi_{i} y_{t-i}\right] .
$$

Expression (51) explains the evolution of the output (and the "true" output gap) as shown in figures 1 and 2. Comparing the dynamics of the output gap when the CB responds to the "true" output gap

\footnotetext{
${ }^{10}$ Note that the result of long-duration business cycles is also obtained in the more general case of inertia in the Phillips curve. To see this, assume that the Phillips curve is given by $\pi_{t}=\beta\left[h E_{t}\left\{\pi_{t+1}\right\}+(1-h) \pi_{t-1}\right]+\kappa \hat{x}_{t}+\lambda \hat{\varphi}_{t}$, where $h$ is the weight of expected inflation and $1-h$ is the weight of lagged inflation. In this case, following the methodology in section 5.2, the output gap is given by $\hat{x}_{t}=\left(1+\frac{\mu_{x}}{\sigma}-\frac{\kappa}{\beta \sigma h}-\frac{\mu_{x}}{\sigma} \chi_{0}\right)^{-1}\left[E_{t}\left\{\hat{x}_{t+1}\right\}+\frac{1}{\beta \sigma h}\left(1+\beta h \mu_{\pi}\right) \pi_{t}-\frac{1-h}{\sigma h} \pi_{t-1}-\frac{\lambda}{\beta \sigma h} \varphi_{t}-\right.$ $\left.\frac{\mu_{x}}{\sigma} \sum_{i=1}^{T-1} \chi_{i} y_{t-i}\right]$
} 
(case A) or, instead, to its measure (case B), in the first period the additional influence on the output gap in case B in comparison with case $\mathrm{A}$ is $-\left(1+\frac{\mu_{x}}{\sigma}-\frac{\kappa}{\beta \sigma}-\frac{\mu_{x}}{\sigma} \chi_{0}\right)^{-1} \frac{\mu_{x}}{\sigma} \chi_{0} y_{t-1}$, a minor influence of less than 1 percent of output as $\mu_{x}=0.125, \sigma=1$, and $\chi_{0}=0.0963$ in the case of a linear trend 11 Thus, in the first period the IRFs of the two cases are quite similar. However, over time, there is an additional influence of lagged output. This influence is reflected by inertia in the output, which delays the convergence to steady state in case $\mathrm{B}$ in comparison with case $\mathrm{A}$. Because $\chi_{i}$ is positive for $i=0,1, \ldots, 14$ and $i=37,38,39$, and negative for the rest of the $i$ 's, and given the fact that in each period there is an additional influence of a different range of lagged output series, in the first twenty periods the output gap in case B is lower than in case A. Twenty periods after the markup shock hits the economy, the influence of the lagged output in case B becomes positive and causes a higher rate of change in output in comparison with case A. Over time, the (positive) influence of the expected output gap and the (negative) influence of inflation 12 decline as the shock fades, and hence output volatility becomes more moderate.

As the model's potential output (and potential interest rate) is not affected by markup shocks, it has no correlation with the HPfiltered output, the linearly detrended output, or any other univariate filtered output trend. However, the relevant question is what the correlation between the true output gap (POG) and its estimates, HPG and LTG, is. In order to answer this question and to better understand the implications of the markup shocks, we conduct Monte Carlo simulations. In each period a random AR(1) markup shock drawn from $\hat{\varphi}_{t} \sim N\left(0, \sigma_{\varphi}^{2}\right)$ hits the economy. The Monte Carlo simulation starts from steady state. In order to have a more reasonable comparison, we drop the first 100 simulation periods and calculate the different output gap estimates and statistics using the rest of the simulated data. We simulate 400,000 periods and calculate the mean of the 1,000 consecutive samples of 400 periods (each reflecting a sample of 100 years).

\footnotetext{
${ }^{11}$ In the baseline calibration, $\left(1+\frac{\mu_{x}}{\sigma}+\frac{\kappa}{\beta \sigma}+\frac{\mu_{x}}{\sigma} \chi_{0}\right)^{-1}$ is 0.886 in case A and 0.876 in case B.

${ }^{12}$ The influence of inflation is similar in both cases because inflation is similar, as shown in figures 1 and 2. The analysis of the expected output gap influence, however, is not complete. A complete analytic analysis is not trivial due to the influence of lagged output on the output gap in case B.
} 
Figure 3 illustrates POG, HPG, and LTG when only markup shocks hit the economy and the $\mathrm{CB}$ responds to the true output gap (when using NKTR) in a simulated period of 100 years. When only markup shocks hit the economy, the correlation between POG and HPG is very high and ranges between $(0.82,090) 13$ while that between POG and LTG is even higher, between $(0.87,0.95)$. However, although correlation is high, the different measures of the output gap differ from the true guidance reflected by the POG with about 17 percent of the cases of the HPG (the upper bar plot) and about 13 percent of the cases of the LTG (the lower bar plot).

\subsection{Technology Shock}

The impulse response function to a positive 1 percent technology shock $(a)$ is shown in figure 4 . First, we analyze the IRF under NKTR and SITR. A positive shock to technology level leads to higher levels of outputs - both actual and potential, although not by the same magnitude. Due to the fading technology shock, expected potential output growth after the first quarter is negative, implying that the potential interest rate declines on impact. Actual output rises by less than potential output. Thus, the output gap (POG) decreases after a positive technology shock. To complete the analysis, following a positive technology shock, (marginal) costs decrease and inflation decreases. Hence, a decrease in the nominal interest rate $(i)$ follows. As the technology shock fades, the economy converges gradually back to steady state.

As in the analysis of the markup shock, the IRFs assuming either NKTR or SITR are monotonic and converge to steady state rapidly, while the IRFs under HPTR or LTTR create long-lasting business cycles, which are much more significant under LTTR (figure 5).

Recall that a positive technology shock raises both output and potential output, with the latter increasing by more, so that the New Keynesian output gap decreases. However, the statistical estimates of the output gap translate the observed rise in output to a lower rise in potential output, and as a result the output gap estimates rise. Hence, the output gap estimates provide misleading indicators about the output gap. Note that the monetary interest rate has a different path under each different policy rule, in contrast with the case of a markup shock only. These different paths contribute further

\footnotetext{
${ }^{13}$ This range reflects a 95 percent confidence interval of the Monte Carlo simulations.
} 


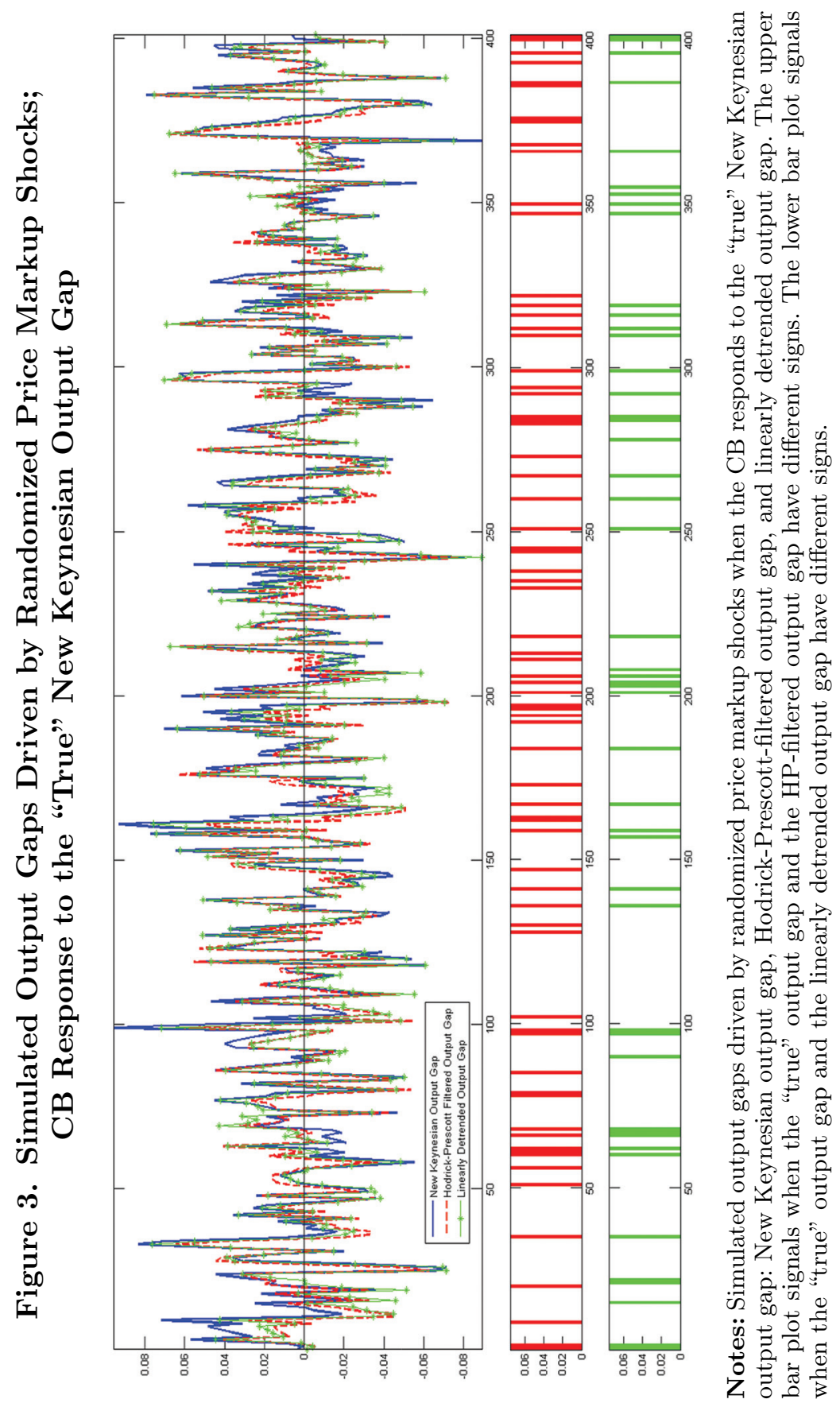




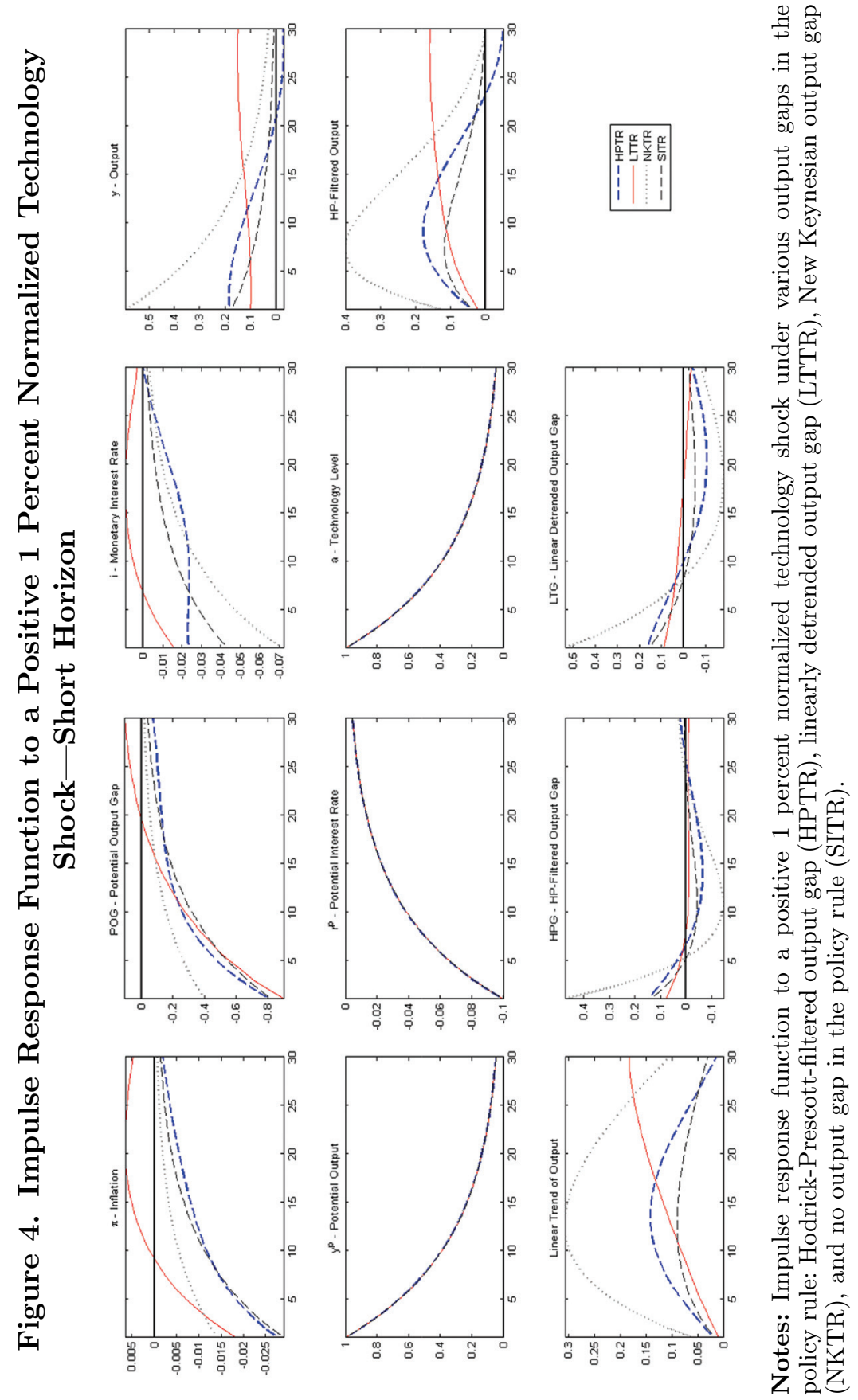



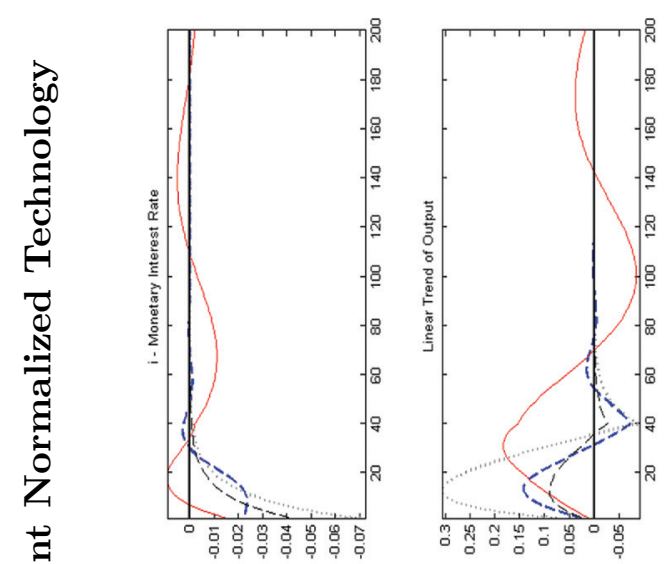

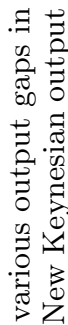

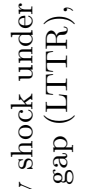
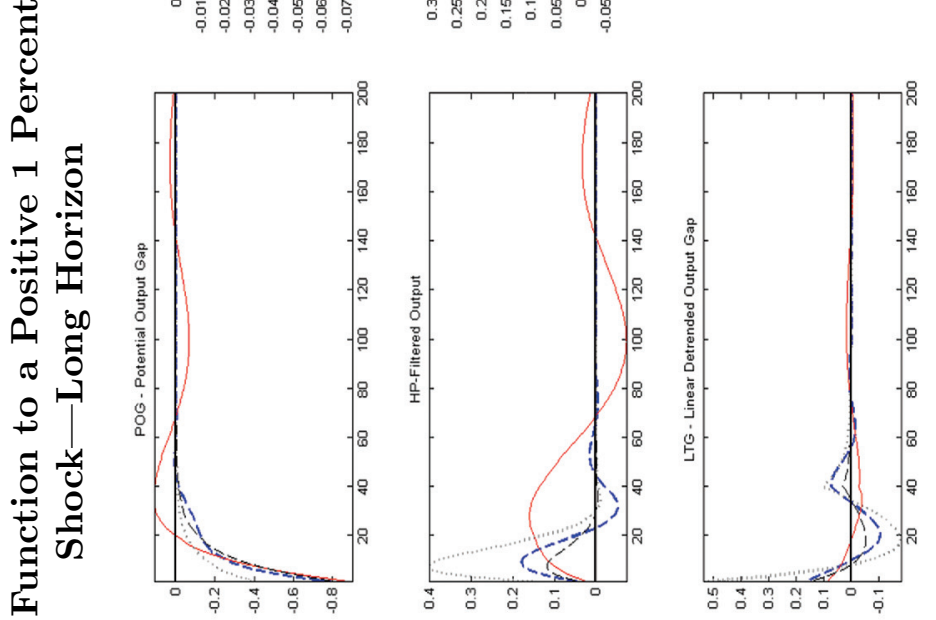

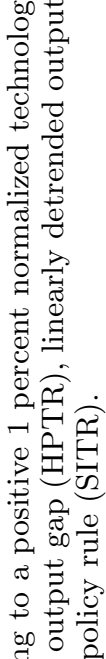
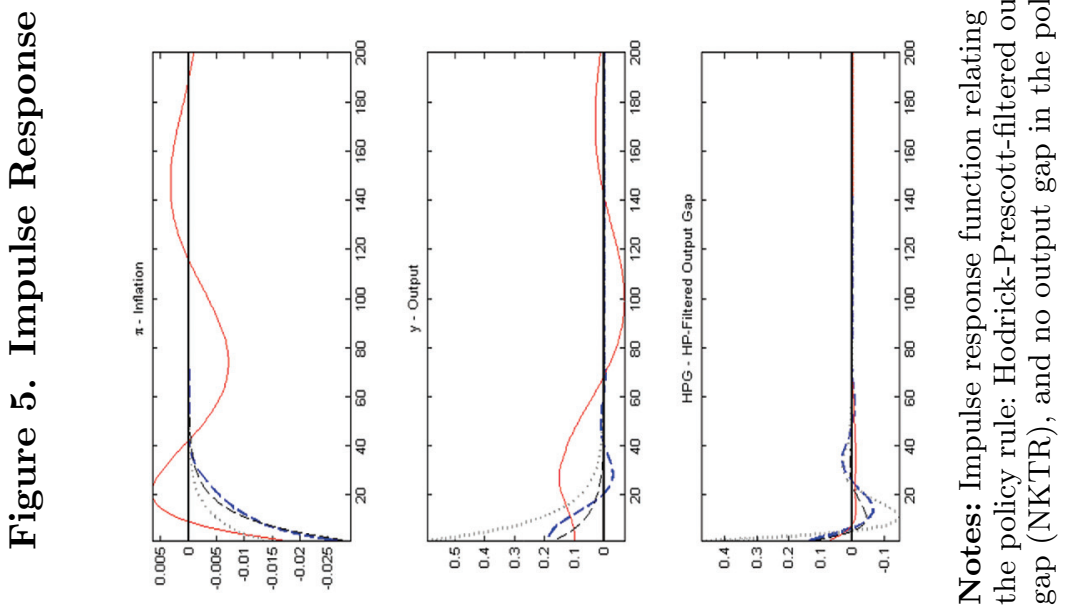
to the different dynamics of the economy under the four alternative policy rules.

Similar to the exercise depicted in figure 3, figure 6 illustrates Monte Carlo simulation of POG, HPG, and LTG when only technology shocks hit the economy. In that case, correlation between POG and HPG is negative and ranges between $(-0.45,-0.16)^{13}$ and correlation between POG and LTG ranges between $(-0.62,-0.26)$. In more than half of the simulated data, the output gap estimates show an opposite sign to that of the true output gap (in about 60 percent of the cases with the HPG and 65 percent with the LTG).

\subsection{Demand Shock}

A preference shock to consumption in the utility function translates to a shock to the dynamic IS equation - a demand-side shock. The impulse response function to a positive normalized 1 percent demand shock (triggered by $\xi$ ) is shown in figure 7 . When the CB uses either NKTR or SITR, a positive demand shock leads to higher potential and actual output, although, again, not by the same magnitude. Actual output increases more than potential output (as opposed to the case of a technology shock). Hence, POG increases as well as inflation. The demand shock, similar to the technology shock, does not create a trade-off between stabilizing policy targets, and thus an increase in the nominal interest rate follows. The minor increase in inflation is due to both the small output gap coefficient in the Taylor rule and the small slope of the NKPC.

Note that the expected potential output growth after the first quarter is negative due to the fading demand shock, and hence the potential interest rate becomes negative on impact. As the demand shock fades, the economy converges gradually but rapidly back to steady state. Comparing NKTR to SITR, in the latter, monetary policy is less contractionary, and hence output and POG are higher 14

\footnotetext{
${ }^{14}$ Note that in the LTTR case, the interest rate is highest in the first twentynine periods, while output and potential output gap are higher in comparison with the NKTR case - and from the tenth period onward are the highest (figure 7). This may seem puzzling, as one can expect according to the IS equation a lower output gap along with a higher interest rate. The puzzle is resolved by realizing that the IS equation relates the monetary interest rate to the New Keynesian potential output gap, while in the LTTR and HPTR cases the central bank responds to the statistical measure of the output gap.
} 


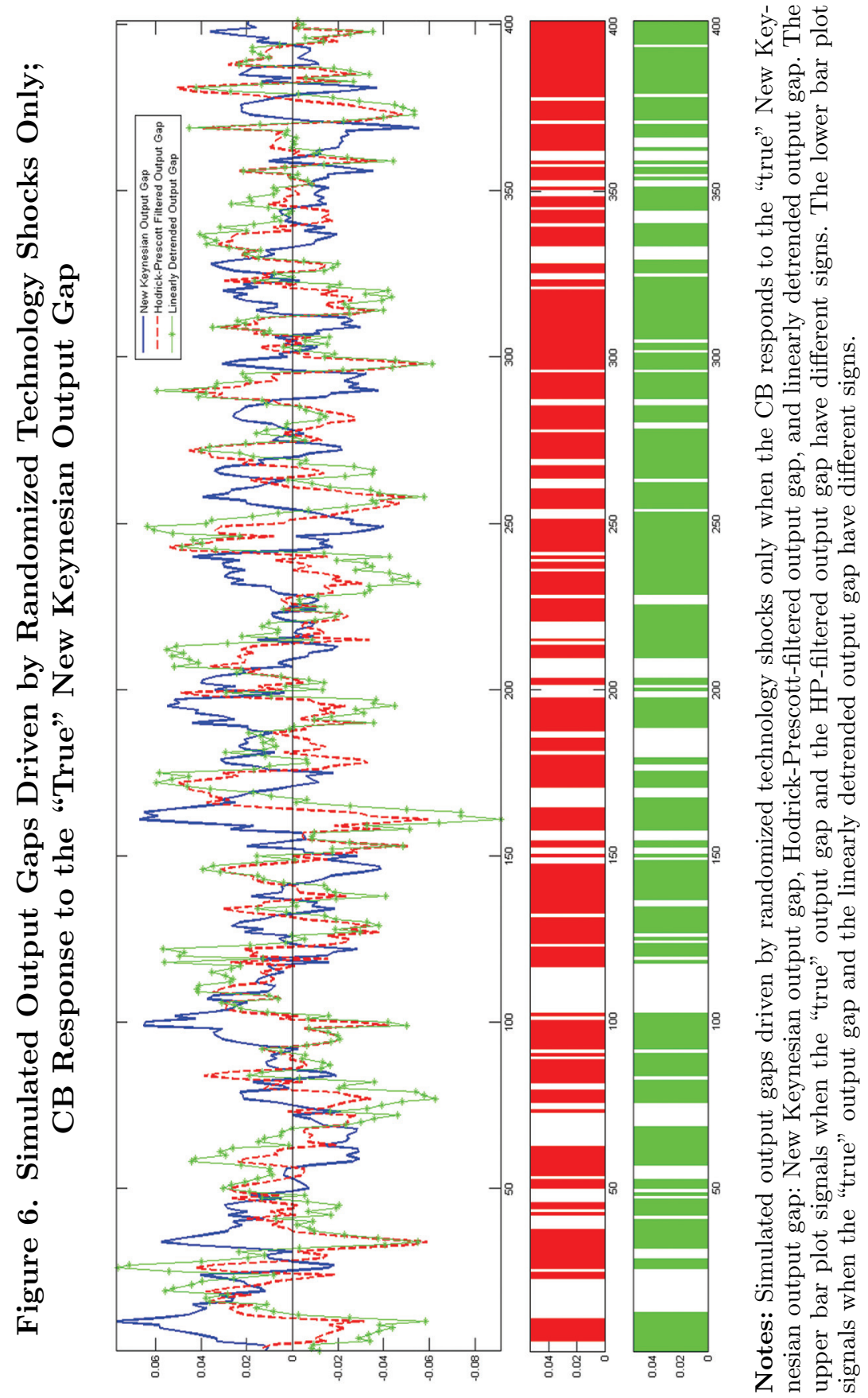




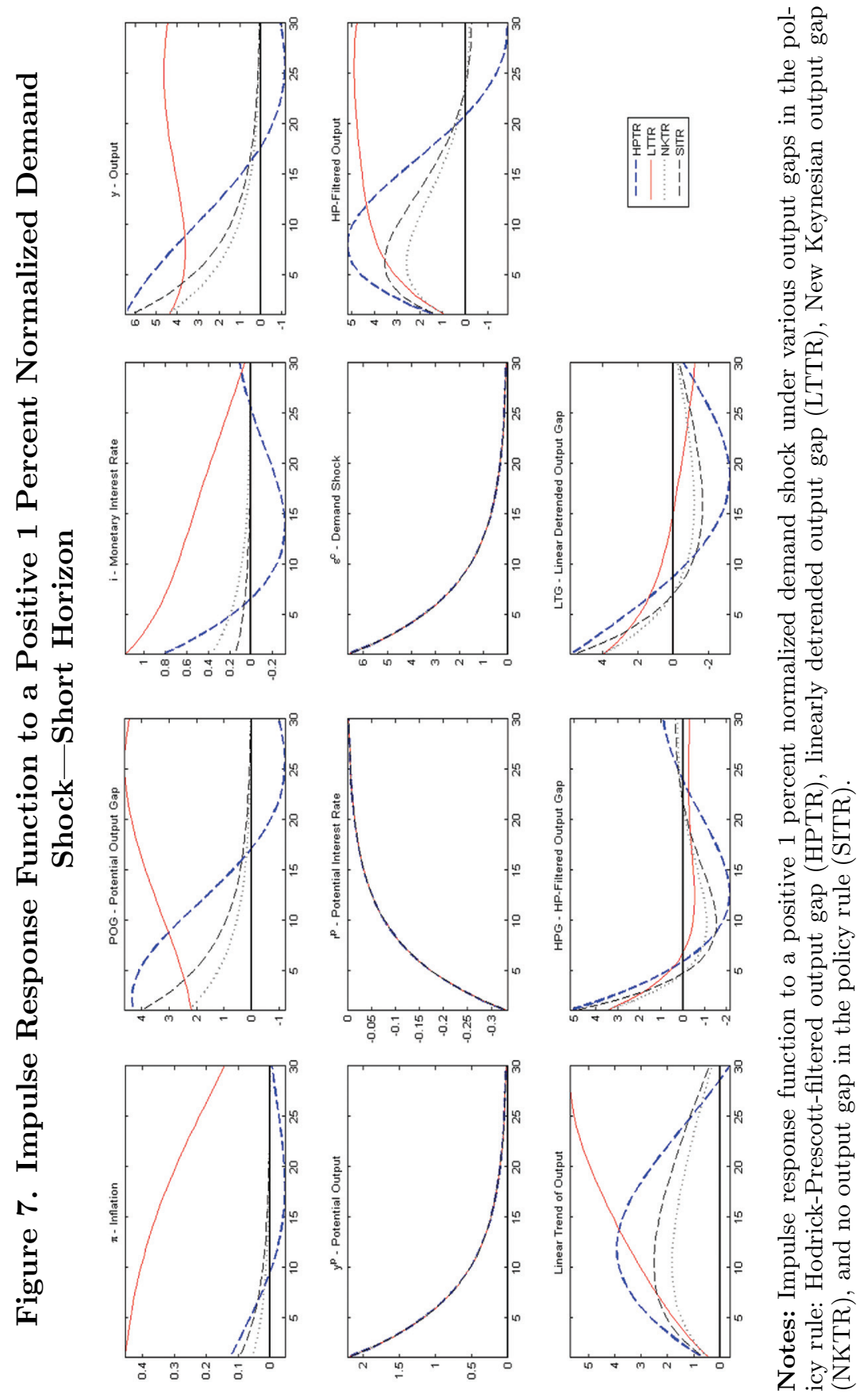


Similar to previous results, when the CB responds to a measure of the output gap (using either HPTR or LTTR, figure 8), a demand shock generates long-lasting business cycles. These business cycles are, again, the most pronounced in the LTTR case, and as a result the interest rate, output gap, and potential output gap are the most volatile. When only demand shocks hit the economy (figure 9), if the $\mathrm{CB}$ responds to the POG, the correlation between POG and its estimates ranges between $(0.30,056)$ for the HPG and slightly higher $(0.42,0.72)$ for the LTG. ${ }^{13}$ In about one-third of the cases the estimate of the output gap signals an erroneous direction of inflationary pressures (36 percent and 31 percent in HPG and LTG, respectively).

The analysis above shows that different shocks affect the economy differently. In section 6 we conduct Monte Carlo simulations in which we let all shocks hit the economy simultaneously, as in reality.

\section{Monte Carlo Simulations-All Shocks Simultaneously}

We showed that each shock affects the economy differently, and particularly on inflation, output, and output gaps. Hence, when all shocks hit the economy simultaneously, correlations between the output gap and its estimates depend on monetary policy as well as on the composition of the shocks.

Figure 10 illustrates a Monte Carlo simulation of the output gap and its estimates when the CB responds to the true output gap (when using NKTR) and all shocks hit the economy. In this case, the high correlation between the output gap and its estimates when only markup shocks hit the economy is offset by the negative correlation when technology shocks hit the economy (table 2, first row).

Table 2 shows that the correlations between the POG and its estimates vary under the different policy rules. When the CB uses either NKTR or SITR, the correlation between the output gap and its estimates is about 0.4. When the CB responds to the HPG, the correlation between the output gap and its estimate drops to 0.25 , and it becomes negative when the CB responds to the LTG. When policy responds only to inflation, the correlations between the output gap and its estimates are the highest (table 2, last row). The correlation between the two estimates of the output gap is high in all policy rules. 


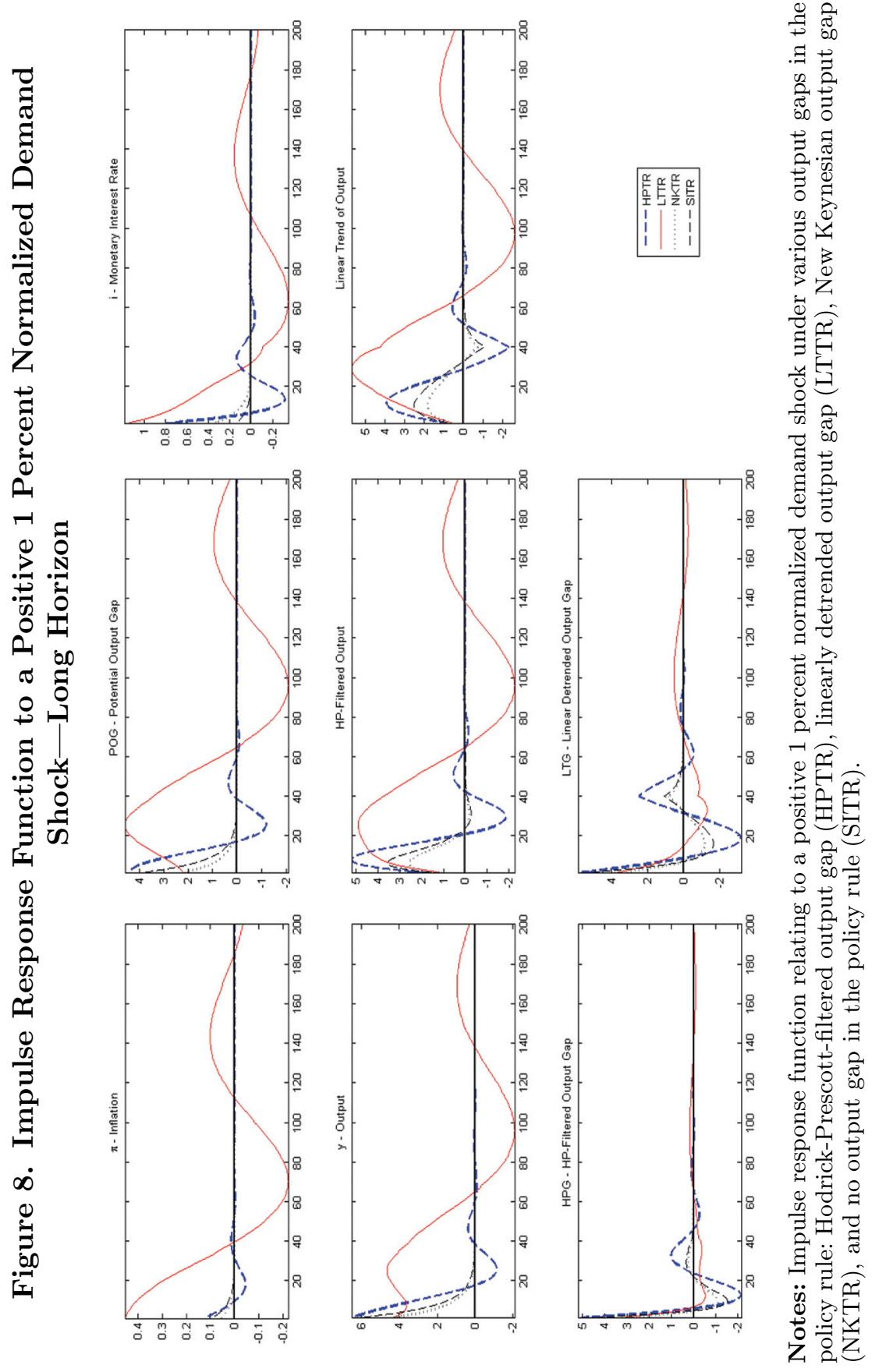




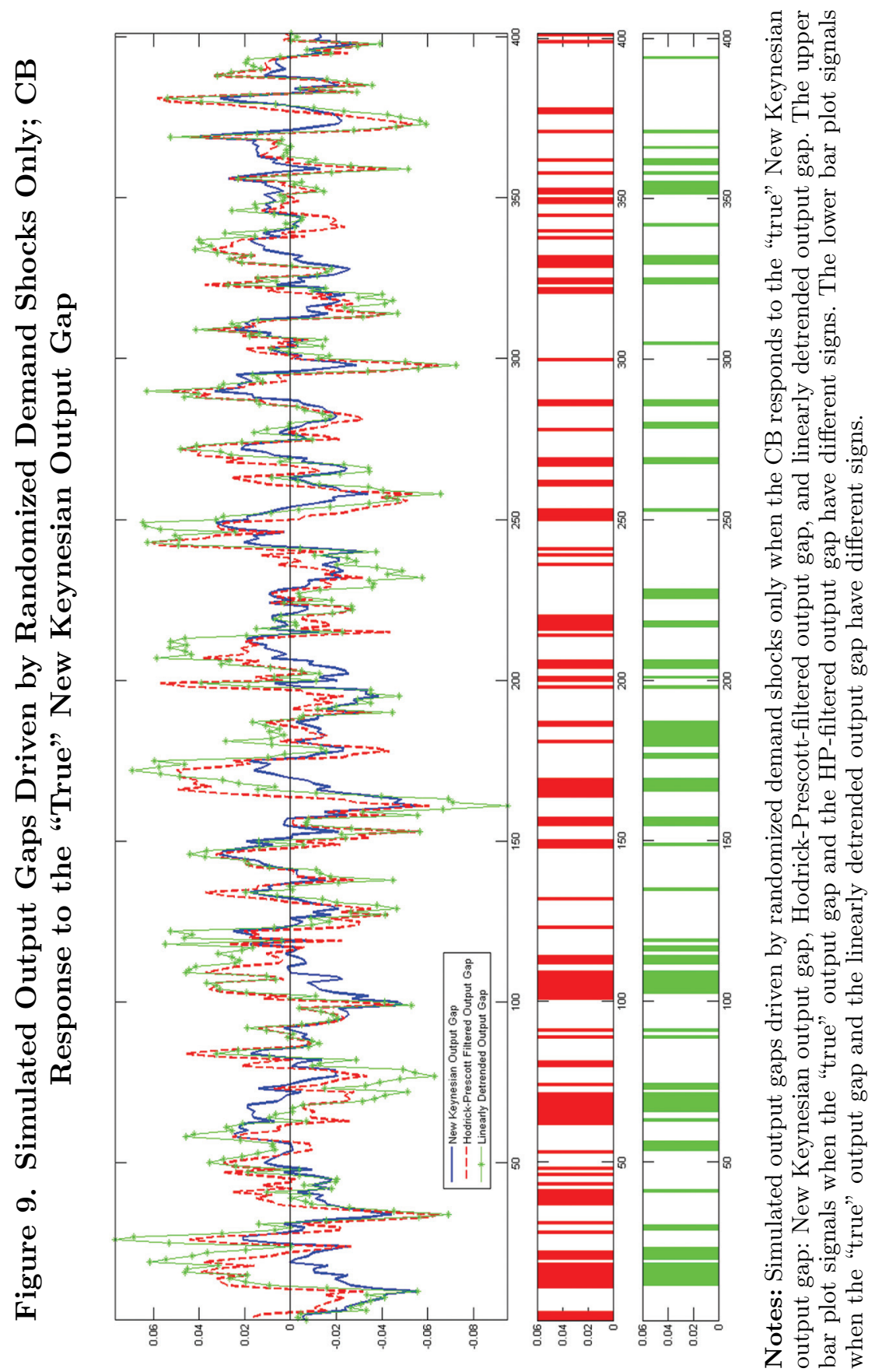




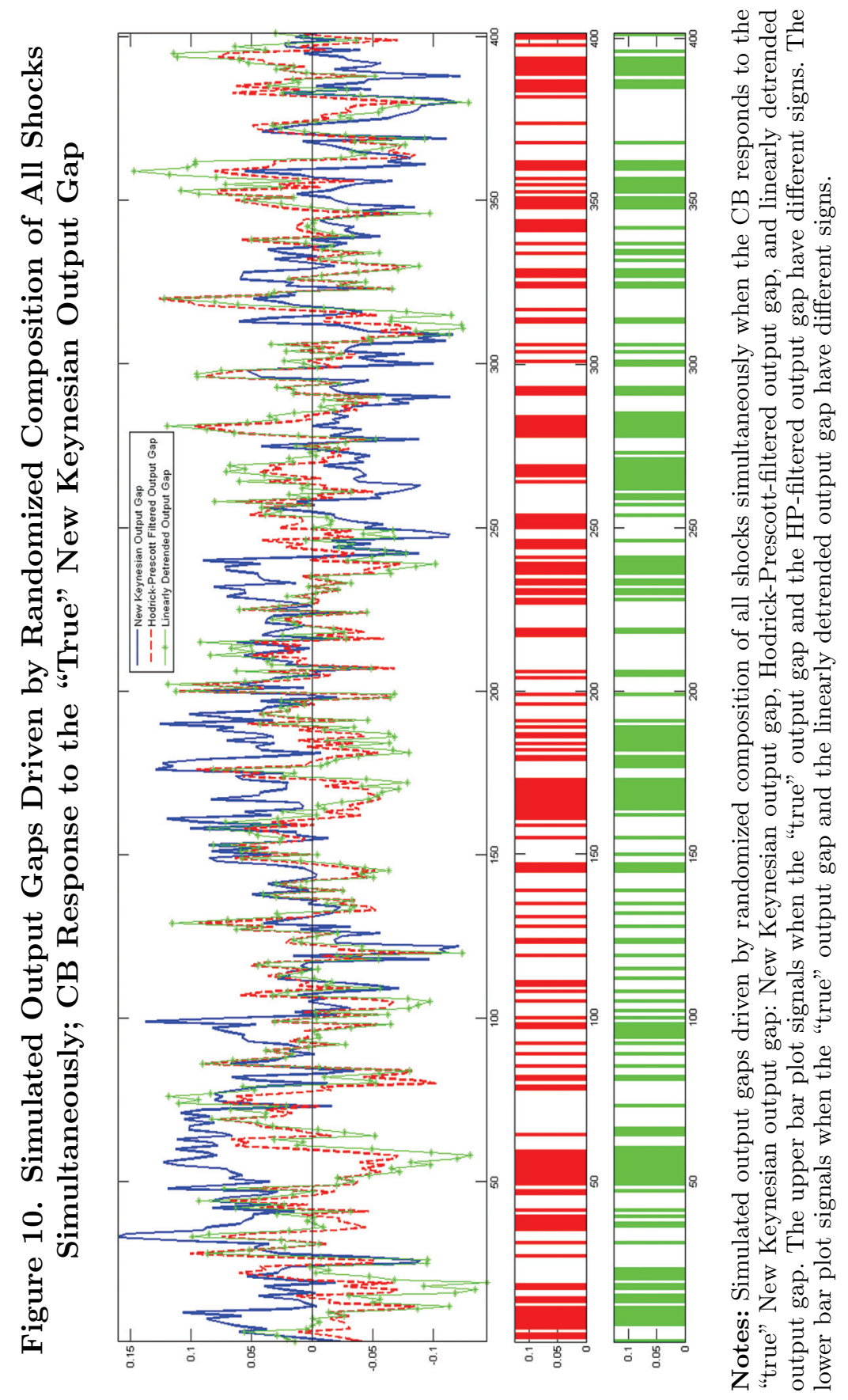




\section{Table 2. Correlations among Different Output Gaps under Different Taylor Rules in the Presence of All Shocks-Simulated Data}

\begin{tabular}{|l|c|c|c|}
\hline & Corr(POG,HPG) & Corr(POG,LTG) & Corr(HPG,LTG) \\
\hline NKTR & 0.38 & 0.33 & 0.84 \\
HPTR & 0.25 & -0.25 & 0.76 \\
LTTR & & 0.42 & 0.84 \\
SITR & 0.40 & 0.86 \\
\hline
\end{tabular}

As the lower bar plots of figure 10 imply, both estimates may provide opposite guidance to monetary policy compared with the "true" output gap, as has been shown empirically (Adolfson et al. 2014; Coenen, Smets, and Vetlov 2008). Thus, the traditional univariate estimates of the New Keynesian output gap are poor guidance indicators for monetary policy.

Figure 11 illustrates a Monte Carlo simulation of the output gap and its estimates when all shocks hit the economy simultaneously if the $\mathrm{CB}$ responds to the LTG. The simulation shows that a response to the LTG instead of to the output gap (figure 10) creates a significant business cycle. This outcome, namely the significant output gap, stands in interesting contrast with Harvey and Jaeger's (1993) result. While responding to the "true" output gap may be accompanied by spurious statistical measures of business cycles (in line with Harvey and Jaeger 1993), when the CB responds either to the HPG or to the LTG it creates real significant business cycles, particularly in the latter case.

Table 3 summarizes the implications of responding to each of the different output gaps, as reflected by the opposite signs of the output gap estimates from the output gap (shown in the bar figures) and by the root mean square deviation (RMSD) among them. This is based on simulated data when all shocks hit the economy. When the CB responds to output gap estimates, the gaps between these estimates and the "true" output gap increase dramatically. Furthermore, these estimates provide misleading guidance about half of the time.

The RMSD of the output gap from its estimate is twofold higher when the CB responds to the HPG and is fourfold higher when the $\mathrm{CB}$ responds to the LTG. In contrast, when the CB responds either 


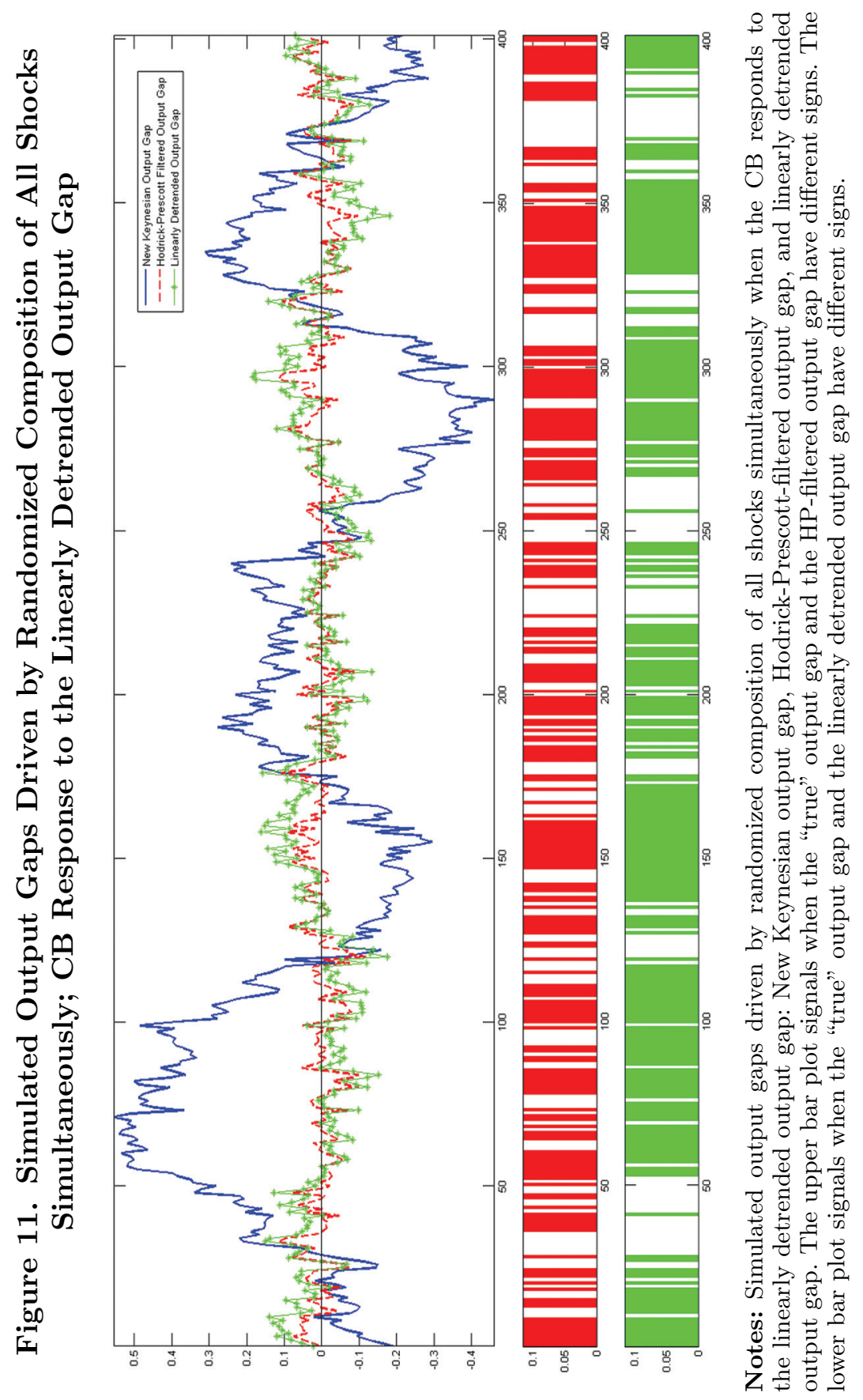




\section{Table 3. Monetary Policy Guidance-Simulated Data-All Shocks}

\begin{tabular}{|l|c|c|c|c|}
\hline \multirow{2}{*}{} & \multicolumn{2}{|c|}{$\begin{array}{c}\text { Percentage of Opposite } \\
\text { Sign Between: }\end{array}$} & \multicolumn{2}{c|}{ RMSD $^{\text {a }}$ Between: } \\
\cline { 2 - 5 } & POG,HPG & POG,LTG & POG,HPG & POG,LTG \\
\hline NKTR & $37.6 \%$ & $39.3 \%$ & $5.1 \%$ & $6.1 \%$ \\
HPTR & $41.9 \%$ & & $9.4 \%$ & $9.3 \%$ \\
LTTR & $37.0 \%$ & $36.1 \%$ & $16.5 \%$ & $18.5 \%$ \\
SITR & & $7.3 \%$ & $7.5 \%$ \\
\hline a Root mean square deviation. \\
\hline
\end{tabular}

to the output gap as well as inflation (NKTR) or only to inflation (SITR), output gap estimates provide misleading guidance about 37 percent of the time, but as the $\mathrm{CB}$ does not respond to these estimates, no harm is done.

\section{Welfare Implications}

The analysis of the IRFs (section 5) and the simulated data (section 6) suggests that the CB response to output gap estimates causes a welfare loss, which is reflected in long-lasting business cycles. Following Rotemberg and Woodford (1997) and Woodford (2003)'s methodology of using a second-order approximation to the expected utility of the representative household, we use the model-based welfare loss function of Galí (2008, pp. 111-12) to evaluate these losses 15:

$$
W=-\frac{1}{2}(1-\Delta) \frac{\varepsilon}{\lambda} E_{0} \sum_{t=0}^{\infty} \beta^{t}\left[\pi_{t}^{2}+\alpha_{1} \hat{x}_{t}^{2}-\alpha_{2} \hat{x}_{t}\right]+t . i . p 16
$$

\footnotetext{
${ }^{15}$ Although we assume stochastic demand elasticity in contrast with Galí's (2008), the model-based welfare loss function is the same under the assumption of zero inflation in the steady state.

${ }^{16}$ A derivation of an optimal discretionary policy rule from a loss function in the case of small distortions in the steady state gives rise to the classical inflation bias, e.g., Galí (2008). Instead, we assume that the CB follows a Taylor rule, and thus avoid this bias.
} 
We define the efficient output gap as the deviation of actual from efficient output:

$$
x_{t} \equiv y_{t}-y_{t}^{e}
$$

We follow Blanchard and Galí (2007) and Sala, Söderström, and Trigari (2010) and define efficient output as output that would prevail in perfect competition and a flexible-price economy, that is, output in an economy with no distortions - neither nominal nor real. Hence, the efficient output is the relevant notion for welfare analysis (see appendix 1 for derivation).

The gap between efficient output and potential output is given by

$$
y_{t}^{e}-y_{t}^{p}=\psi_{y \varphi}^{p} \varphi=\frac{1-\alpha}{\sigma(1-\alpha)+\eta+\alpha} \varphi .
$$

When firms have monopolistic power, efficient output is higher than potential output by a constant term, which is a function of the real distortion in the economy resulting from the monopolistic power of the firms. In perfect competition, both potential and efficient outputs equal each other. Using standard calibration, we can quantify the loss of output due to the monopolistic power of the firms. A 20 percent price markup in the steady state implies, using equation (6), a loss of 6.1 percent of output. As $\hat{\varphi}_{t} \equiv \log \left(\Phi_{t} / \Phi\right)$, it also implies that $\hat{\varphi}_{t} \in(-0.182, \infty)$ - that is, the price markup shock is bounded from below. Note that when firms have monopolistic power, efficient output is also always higher than natural output, as expected. The gap between the two is not constant, and it is proportional to the monopolistic power captured by $\varphi_{t}$ (appendix 1 ).

$\alpha_{1} \equiv \kappa / \varepsilon, \alpha_{2} \equiv 2 \lambda \Delta / \varepsilon$, and t.i.p. is terms independent of policy. $\Delta$ denotes distortion stemming from monopolistic competition in steady state, and is defined as the distortion that equates the marginal product of labor to the marginal rate of substitution: $-U_{n} / U_{c}=\operatorname{MPN}(1-\Delta)$, implying $\Delta=\varepsilon^{-1}$. Apart from welfare losses captured by the squared deviations of inflation and efficient output gap (due to price dispersion as prices are staggered and distortions in the allocation of consumption due to relative price distortions), in the case of a distorted steady state, the welfare loss function also includes a negative linear term of the efficient output gap. This term reflects the positive effect of an increase in output on 
welfare as output is below its efficient level due to the monopolistic power of the firms.

The welfare loss function is expressed in terms of a fraction of steady-state consumption.

\subsection{The Basic Calibration-Taylor (1993) Coefficients}

Table 4 summarizes the welfare implications of responding to the different output gaps, as expressed by the loss function (equation (6)), using the coefficients in the original Taylor rule (Taylor 1993) $\mu_{\pi}=1.5$ and $\mu_{x}=0.5 / 4$. Following Orphanides et al. (2000), we also examine the welfare implications of responding to the last four quarters' output growth-GTR (table 4, last row), rather than to the output gap or one of its measures.

When the CB responds to the LTG, the welfare loss is about 20 percent higher than the loss under the other alternatives. However, the loss function does not capture the further welfare loss which occurs when the $\mathrm{CB}$ responds to the HPG. The reason is the minor weight of the efficient output gap in the loss function stemming from the small slope of the Phillips curve - the inflation elasticity with respect to output gap. However, the variance of output is doubled under the HPTR, and almost doubled under the GTR compared with the NKTR and the SITR alternatives-reflecting the longduration business cycles created under the HPTR and the GTR. When the CB responds to the LTG, the output variance is six times higher than in the case of using either NKTR or SITR.

Table 4. Welfare Implications of Using Different Taylor Rules-Welfare Loss in Terms of Discounted Fraction of Steady-State Consumption (average annual loss, percent)

\begin{tabular}{|l|c|l|l|l|l|}
\hline & Welfare Loss & Loss $(\hat{\boldsymbol{x}})$ & Loss $(\boldsymbol{\pi})$ & $\operatorname{Var}(\boldsymbol{y})$ & $\operatorname{Var}(\boldsymbol{\pi})$ \\
\hline NKTR & $-0.976 \%$ & $-0.003 \%$ & $-0.973 \%$ & $0.42 \%$ & $0.05 \%$ \\
HPTR & $-0.986 \%$ & $-0.010 \%$ & $-0.976 \%$ & $0.80 \%$ & $0.05 \%$ \\
LTTR & $-1.187 \%$ & $-0.032 \%$ & $-1.155 \%$ & $2.41 \%$ & $0.06 \%$ \\
SITR & $-0.984 \%$ & $-0.007 \%$ & $-0.977 \%$ & $0.45 \%$ & $0.05 \%$ \\
GTR & $-0.973 \%$ & $-0.010 \%$ & $-0.963 \%$ & $0.72 \%$ & $0.05 \%$ \\
\hline
\end{tabular}




\section{Table 5. Variance of the Different Output Gaps under Different Monetary Rules (percent)}

\begin{tabular}{|l|c|c|c|}
\hline & VAR (POG) & VAR (HPG) & VAR (LTG) \\
\hline NKTR & $0.22 \%$ & $0.19 \%$ & $0.32 \%$ \\
HPTR & $0.82 \%$ & $0.34 \%$ & \\
LTTR & $2.61 \%$ & & $0.34 \%$ \\
SITR & $0.60 \%$ & $0.23 \%$ & $0.37 \%$ \\
GTR & $0.79 \%$ & $0.26 \%$ & $0.54 \%$ \\
\hline
\end{tabular}

While GTR yields the lowest welfare loss - although quite similar to the NKTR and slightly less than the SITR - the variance of output is almost doubled under the GTR compared with the NKTR and the SITR alternatives, and only slightly below that under the HPTR.

While the volatility of the inflation rate is not sensitive to monetary policy (table 4), the volatilities of the New Keynesian output gap and its estimates do depend on monetary policy (table 5). If the $\mathrm{CB}$ responds to the New Keynesian output gap, volatilities are about the same. However, when the CB responds to an output gap estimate, the volatility of the New Keynesian output gap rises dramatically, while the volatility of the estimate is slightly higher than in the case when the CB responds to the New Keynesian output gap.

When the CB responds only to inflation, efficient output gap volatility is about three times higher than when it responds to the efficient output gap; it is about four times higher when it responds to the HPG or to output growth; and it is about twelve times higher when it responds to the LTG. Note that the volatility of the LTG estimate of the output gap is similar among the different monetary policy rules, but under GTR it is almost doubled.

\subsection{Optimal Output Gap Coefficient in the Taylor Rule}

In this subsection, we follow the welfare analysis conducted in Orphanides et al. (2000). Specifically, we hold the coefficient of the inflation rate fixed $\left(\mu_{\pi}=1.5\right)$ and use a grid search for $\mu_{x}=\{[0, \ldots, 0.25]$ by 0.025$\}$, which minimizes the welfare loss function (equation (6)). As above, we simulate 400,000 periods and 


\section{Table 6. Optimal Output Gap Coefficient and the Corresponding Welfare Loss in Terms of Discounted Fraction of Steady-State Consumption (average annual loss, percent)}

\begin{tabular}{|l|c|c|c|c|c|c|}
\hline & Optimal $\boldsymbol{\mu}_{\boldsymbol{x}}$ & $\begin{array}{c}\text { Welfare } \\
\text { Loss }\end{array}$ & Loss $(\hat{\boldsymbol{x}})$ & Loss $(\boldsymbol{\pi})$ & $\operatorname{Var}(\boldsymbol{y})$ & $\operatorname{Var}(\boldsymbol{\pi})$ \\
\hline NKTR & $0.2-0.25$ & $-0.975 \%$ & $-0.002 \%$ & $-0.973 \%$ & $0.42 \%$ & $0.050 \%$ \\
HPTR & 0.050 & $-0.983 \%$ & $-0.008 \%$ & $-0.975 \%$ & $0.53 \%$ & $0.051 \%$ \\
LTTR & 0.025 & $-0.982 \%$ & $-0.008 \%$ & $-0.974 \%$ & $0.53 \%$ & $0.051 \%$ \\
SITR & 0 & $-0.984 \%$ & $-0.007 \%$ & $-0.977 \%$ & $0.44 \%$ & $0.050 \%$ \\
GTR & $0.2-0.225$ & $-0.968 \%$ & $-0.013 \%$ & $-0.955 \%$ & $0.93 \%$ & $0.049 \%$ \\
\hline
\end{tabular}

calculate the mean of the 1,000 consecutive samples of 400 periods (each reflecting a sample of 100 years). Table 6 summarizes the results.

Table 6 shows that each of the various optimal responses of the $\mathrm{CB}$ to the output gap or to its measures leads to similar welfare losses. The optimal output gap coefficients reflect attenuation - that is, the optimal coefficients of the output gap measures are only slightly above zero, similar to Orphanides et al. (2000) findings and as is observed empirically by Smets (2002). In contrast, the optimal coefficient under NKTR, as well as under GTR, is in the range of 0.2-0.25, similar to the updated Taylor rule (Taylor 1999). However, if the CB responds to output growth, the variance of output is more than doubled compared with the NKTR and the SITR alternatives. Hence, all in all, it is preferable that the central bank responds only to inflation.

\section{Summary and Conclusion}

The heart of the research question in this paper is the identification of the unobserved output gap using traditional statistical filters and the implications of using such measures. We use Monte Carlo simulations of the canonical New Keynesian model to analyze the positive and the welfare implications of responding to either a HodrickPrescott-filtered output gap or a linearly detrended output gapinstead of to the model-based New Keynesian output gap. 
We find that responding to output gap estimates creates longlasting business cycles as well as welfare loss. These business cycles are created due to the fact that both the Hodrick-Prescott-filtered output and the linearly detrended output measure potential output by smoothing the output series regardless of the source of the shock hitting the economy and hence fail to identify the "true" output gap. The particular combination of the various shocks, as implied by the standard deviation and inertia of each one, determines the implications of responding to a statistical measure of the output gap on the economy. Moreover, following a technology shock, these estimators provide misleading guidance to monetary policy, a result which is also present in the cases of price shocks (cost-push shocks) and demand shocks, although to a smaller extent.

The long duration of the business cycles is explained by the fact that the estimates are derived from historical output data, which introduce inertia into the estimated output gap series. The implications of responding to a linearly detrended output gap are found to be the most pronounced due to the smoother weights attached to historical output, compared with the weights in the Hodrick-Prescott filter.

As the output gap is unobserved, we find that it is preferable that the central bank responds only to inflation and not to the output gap estimates.

\section{Appendix 1. The Model's Derivation}

We rely heavily on the methodology of Galí (2008) to derive the model's equations.

\section{The Households Problem}

A representative infinitely lived household maximizes its expected discounted lifetime utility:

$$
E_{0} \sum_{t=0}^{\infty} \beta^{t} U\left(C_{t}, N_{t}\right),
$$


where the constant relative risk aversion (CRRA) utility function is given by

$$
U\left(C_{t}, N_{t}\right)=\Xi_{t} \frac{C_{t}^{1-\sigma}}{1-\sigma}-\frac{N_{t}^{1+\eta}}{1+\eta},
$$

and where $C_{t}$ is an elasticity of substitution consumption index of a continuum goods $i \in(0,1]$, given by

$$
C_{t} \equiv\left(\int_{0}^{1} C_{t}(i)^{\frac{1}{\Phi_{t}}} d i\right)^{\Phi_{t}}
$$

$C_{t}(i)$ denotes the quantity of good $i$ consumed by the household, $N_{t}$ denotes its labor supply, and $\Phi_{t}>1$ is inversely related to the elasticity of substitution among goods $-\varepsilon_{t} \equiv \Phi_{t} /\left(\Phi_{t}-1\right) . \Xi_{t}$ is a preference shock to consumption (e.g., Cristoffel, Coenen, and Warne 2008 and Smets and Wouters 2003a).

The household budget constraint is given by

$$
\int_{0}^{1} P_{t}(i) C_{t}(i) d i+Q_{t} B_{t} \leq B_{t-1}+W_{t} N_{t}+T A X_{t}
$$

where $P_{t}(i)$ is the price of good $i$. $B_{t}$ denotes one-period-ahead bond units purchased by the household in the price of $Q_{t}$ per bond, $W_{t}$ is nominal wage, and $T A X_{t}$ denotes lump-sum taxes. The solution of the optimal consumption allocation for given expenditures yields the demand function:

$$
C_{t}(i)=\left(\frac{P_{t}(i)}{P_{t}}\right)^{-\frac{\Phi_{t}}{\Phi_{t}-1}} C_{t}
$$

where aggregate price index is given by $P_{t} \equiv\left(P_{t}(i)^{\frac{1}{1-\Phi_{t}}} d i\right)^{1-\Phi_{t}}$.

Hence, $\int_{0}^{1} P_{t}(i) C_{t}(i) d i=P_{t} C_{t}$, implying that the budget constraint can be written as $P_{t} C_{t}+Q_{t} B_{t} \leq B_{t-1}+W_{t} N_{t}+T A X_{t}$.

The first-order conditions with regard to consumption, labor, and bonds yield the standard intratemporal optimal condition, the optimal labor supply condition which equates real wage to marginal rate of substitution (MRS),

$$
\frac{W_{t}}{P_{t}}=\frac{C_{t}^{\sigma} N_{t}^{\eta}}{\Xi_{t}}
$$


and the intertemporal condition, the Euler, which is given by

$$
Q_{t}=\beta E_{t}\left\{\left(\frac{\Xi_{t+1}}{\Xi_{t}}\right)\left(\frac{C_{t+1}}{C_{t}}\right)^{-\sigma}\left(\frac{P_{t}}{P_{t+1}}\right)\right\} .
$$

Log-linearizing the first-order conditions - (13) and (14) - yields

$$
w_{t}-p_{t}=\sigma c_{t}+\eta n_{t}-\xi_{t}
$$

and

$$
c_{t}=E_{t}\left(c_{t+1}\right)-\frac{1}{\sigma}\left(i_{t}-E_{t}\left(\pi_{t+1}\right)-\rho\right)+\frac{1}{\sigma}\left(1-\rho^{\xi}\right) \xi_{t},
$$

where $i_{t} \equiv-\log Q_{t}$ is the nominal interest rate, $\rho \equiv-\log \beta$ is the time discount rate, $\pi_{t} \equiv p_{t}-p_{t-1}$ is the CPI inflation rate, and $\rho^{\xi}$ is the preference shock to consumption persistence. $\xi_{t} \equiv \log \left(\Xi_{t}\right)$ denotes the preference shock, which follows an $\operatorname{AR}(1)$ process $\xi_{t}=\rho^{\xi} \xi_{t-1}+\nu_{t}^{\xi}$, where $\nu_{t}^{\xi}$ is white noise.

As the model is a closed-economy model without investment and government, output, $y_{t}$, equals consumption. Hence, the consumer's Euler equation (16) yields the equilibrium condition:

$$
y_{t}=E_{t}\left(y_{t+1}\right)-\frac{1}{\sigma}\left(i_{t}-E_{t}\left(\pi_{t+1}\right)-\rho\right)+\frac{1}{\sigma}\left(1-\rho^{\xi}\right) \xi_{t} .
$$

\section{Technology}

Each firm $i \in(0,1]$ uses the production function

$$
Y_{t}(i)=A_{t} N_{t}(i)^{1-\alpha}
$$

to produce its differentiated good, where $N_{t}(i)$ denotes labor in firm $i$ and $A_{t}$ is the productivity level affecting all firms. Productivity evolves according to the $\operatorname{AR}(1)$ process $a_{t}=\rho^{a} a_{t-1}+v_{t}^{a}$, where $a_{t} \equiv \log \left(A_{t}\right)$ and $v_{t}^{a}$ is white noise. 
Derivation of the New Keynesian Phillips Curve

The optimal price $P_{t}^{*}$ is set to maximize the discounted flow of profits:

$$
\underset{P_{t}^{*}}{\operatorname{Max}} \sum_{k=0}^{\infty} \theta^{k} E_{t}\left\{Q_{t, t+k}\left(P_{t}^{*} Y_{t+k \mid t}-\Psi_{t+k}\left(Y_{t+k \mid t}\right)\right\}\right.
$$

subject to the demand constraint

$$
Y_{t+k \mid t}=\left(\frac{P_{t}^{*}}{P_{t+k}}\right)^{-\frac{\Phi_{t+k}}{\Phi_{t+k}-1}} Y_{t+k} .
$$

$Y_{t+k \mid t}$ is output in period $t+k$ for a firm that last optimized its price in period $t$, and $Q_{t, t+k} \equiv \beta^{k}\left(C_{t+k} / C_{t}\right)^{-\sigma}\left(P_{t} / P_{t+k}\right)$ is the stochastic discount factor for nominal payoffs, derived from iterating the Euler equation (16) forward. $\Psi(\cdot)$ is the cost function of the firm.

The first-order condition of the firm's problem is given by

$$
\sum_{k=0}^{\infty} \theta^{k} E_{t}\left\{Q_{t, t+k}\left[Y_{t+k \mid t}+P_{t}^{*} \frac{\partial Y_{t+k \mid t}}{\partial P_{t}^{*}}-\psi_{t+k \mid t} \frac{\partial Y_{t+k \mid t}}{\partial P_{t}^{*}}\right]\right\}=0,
$$

where $\psi_{t+k \mid t} \equiv \Psi_{t+k}^{\prime}\left(Y_{t+k \mid t}\right)$ is the nominal marginal cost in period $t+k$.

$$
\begin{aligned}
& \text { As } \frac{\partial Y_{t+k \mid t}}{\partial P_{t}^{t}}=-\frac{\Phi_{t+k}}{\Phi_{t+k}-1} \frac{1}{P_{t}^{*}} Y_{t+k \mid t} \text {, we get } \\
& \left.\sum_{k=0}^{\infty} \theta^{k} E_{t}\left\{Q_{t, t+k} Y_{t+k \mid t}\left[\left(1-\frac{\Phi_{t+k}}{\Phi_{t+k}-1}\right)+\frac{1}{P_{t}^{*}} \frac{\Phi_{t+k}}{\Phi_{t+k}-1} \psi_{t+k \mid t}\right)\right]\right\}=0 .
\end{aligned}
$$

Multiplying by $P_{t}^{*}$ and dividing by $1-\frac{\Phi_{t+k}}{\Phi_{t+k}-1}$, we can express this as

$$
\sum_{k=0}^{\infty} \theta^{k} E_{t}\left\{Q_{t, t+k} Y_{t+k \mid t}\left(P_{t}^{*}-\Phi_{t+k} \psi_{t+k \mid t}\right)\right\}=0,
$$

where $\Phi_{t+k}=\frac{\varepsilon_{t+k}}{\varepsilon_{t+k}-1}$ is interpreted as the desired markup charged by the firm; when demand elasticity decreases, the monopolists can 
charge a higher markup, which reflects a higher market power of the firm.

Note that when prices are flexible, the first-order condition in (22) implies that the optimal price is set as a desired markup over the firm's nominal marginal cost.

The first-order condition (22) can be written as

$$
\sum_{k=0}^{\infty} \theta^{k} E_{t}\left\{Q_{t, t+k} Y_{t+k \mid t}\left(\frac{P_{t}^{*}}{P_{t-1}}-\Phi_{t+k} M C_{t+k \mid t} \Pi_{t-1, t+k}\right)\right\}=0
$$

where $\Pi_{t, t+k} \equiv P_{t+k} / P_{t}$ and $M C_{t+k \mid t} \equiv \psi_{t+k \mid t} / P_{t+k}$ is the real marginal cost in period $t+k$ for a firm which set its price in period $t$.

In a zero-inflation steady state, $P_{t} / P_{t-1}=1$ and $\Pi_{t-1, t+k}=1$. Hence $Y_{t+k \mid t}=Y$ and $M C_{t+k \mid t} \equiv M C$, as all firms produce the same quantity of output in the steady state, and $Q_{t, t+k}=\beta^{k}$. Accordingly, $M C=1 / \Phi$. Thus, a first-order Taylor expansion of (23) around the zero-inflation steady state yields

$$
p_{t}^{*}-p_{t-1}=(1-\beta \theta) \sum_{k=0}^{\infty}(\beta \theta)^{k} E_{t}\left\{\hat{m} c_{t+k \mid t}+\left(p_{t+k}-p_{t-1}\right)+\hat{\varphi}_{t+k}\right\},
$$

where $\hat{m} c_{t+k \mid t} \equiv m c_{t+k \mid t}-m c$ is the log-deviation of real marginal cost from its steady-state value $m c=-\varphi$, where $\varphi \equiv \log (\Phi)$. Following Galí (2008), we assume an exogenous $\operatorname{AR}(1)$ process for $\hat{\varphi}_{t}, \hat{\varphi}_{t}=\rho^{\varphi} \hat{\varphi}_{t-1}+v_{t}^{\varphi}$, where $v_{t}^{\varphi}$ is white noise.

The economy's real marginal cost is defined as the ratio of real wage to marginal product of labor:

$$
M C_{t} \equiv \frac{1}{P_{t}} \frac{\partial T C_{t}}{\partial Y_{t}}=\frac{1}{P_{t}} \frac{\partial T C_{t}}{\partial Y_{t}} \frac{\partial N_{t}}{\partial N_{t}}=\frac{1}{P_{t}} \frac{\partial T C_{t}}{\partial N_{t}} / \frac{\partial Y_{t}}{\partial N_{t}}=\frac{W_{t}}{P_{t}} / M P N_{t} .
$$

Using the production function (18), the economy's average real marginal cost is

$$
m c_{t}=\left(w_{t}-p_{t}\right)-(1-\alpha)^{-1}\left(a_{t}-\alpha y_{t}\right)-\log (1-\alpha) .
$$

Hence, $m c_{t+k \mid t}=m c_{t+k}+\frac{\alpha}{1-\alpha}\left(y_{t+k \mid t}-y_{t+k}\right)$. 
Next, using the demand function (19) and market clearing condition,

$$
\hat{m} c_{t+k \mid t}=\hat{m} c_{t+k}-\frac{\alpha}{1-\alpha} \frac{\varphi}{\varphi-1}\left(p_{t}^{*}-p_{t+k}\right) .
$$

Substituting (27) into (24) yields

$$
p_{t}^{*}-p_{t-1}=\beta \theta E_{t}\left\{p_{t+1}^{*}-p_{t}\right\}+(1-\beta \theta) \Theta\left(\hat{m} c_{t}+\hat{\varphi}_{t}\right)+\pi_{t},
$$

where $\Theta \equiv \frac{\varphi-1+\alpha-\alpha \varphi}{\varphi-1+\alpha} \leq 1$.

Log-linearizing the aggregate price index around the zero steadystate inflation implies that $\pi_{t}=(1-\theta)\left(p_{t}^{*}-p_{t-1}\right)$, which together with (28) yields the Phillips curve in terms of log-deviation of marginal cost and the desired markup from steady state:

$$
\pi_{t}=\beta E_{t}\left\{\pi_{t+1}\right\}+\lambda\left(\hat{m} c_{t}+\hat{\varphi}_{t}\right),
$$

where $\lambda \equiv \frac{(1-\beta)(1-\beta \theta)}{\theta} \Theta$.

\section{Potential Output and Potential Real Interest Rate}

The average real marginal cost, the gap between the real wage and the marginal product of labor (26) , along with the optimal labor supply condition (15) and the production function (18), yield the next relation between the economy's real marginal cost and aggregate activity:

$$
m c_{t}=\left(\sigma+\frac{\eta+\alpha}{1-\alpha}\right) y_{t}-\frac{1+\eta}{1-\alpha} a_{t}-\log (1-\alpha)-\xi_{t} .
$$

Using this expression, and defining potential output, $y_{t}^{p}$, as output which would prevail in a flexible-price economy when price markup shocks are held constant at steady-state values, 17 real marginal cost is given by $m c_{t}=-\varphi 18$ Hence, potential output satisfies the equation

$$
-\varphi=\left(\sigma+\frac{\eta+\alpha}{1-\alpha}\right) y_{t}^{p}-\frac{1+\eta}{1-\alpha} a_{t}-\log (1-\alpha)-\xi_{t} .
$$

\footnotetext{
${ }^{17}$ Following Adolfson et al. (2014), Sala, Söderström, and Trigari (2010), Smets and Wouters (2003a, 2003b), and Woodford (2003).

${ }^{18}$ This relation is derived from equation (22) when prices are flexible.
} 
Thus, potential output is given by

$$
y_{t}^{p}=\psi_{y a}^{p} a_{t}-\psi_{y \varphi}^{p} \varphi+\psi_{y \varphi}^{p} \xi_{t}+\vartheta_{y}^{p}
$$

where $\psi_{y a}^{p} \equiv \frac{1+\eta}{\sigma(1-\alpha)+\eta+\alpha}, \quad \psi_{y \varphi}^{p} \equiv \frac{1-\alpha}{\sigma(1-\alpha)+\eta+\alpha}$, and $\vartheta_{y}^{p} \equiv$ $\frac{(1-\alpha) \log (1-\alpha)}{\sigma(1-\alpha)+\eta+\alpha}$.

Using (30) and (31), the log-deviation of the economy's real marginal cost from steady state of potential economy, $\hat{m} c_{t}$, is given by

$$
\hat{m} c_{t}=\left(\sigma+\frac{\eta+\alpha}{1-\alpha}\right)\left(y_{t}-y_{t}^{p}\right)
$$

Denoting the potential output gap as $\tilde{y}_{t} \equiv y_{t}-y_{t}^{p}$ and plugging (33) in (29) yields the NK Phillips curve (NKPC) in terms of the potential output gap (equation (1) ), where $\kappa \equiv \lambda\left(\sigma+\frac{\eta+\alpha}{1-\alpha}\right)$.

Substituting the potential output gap expression into the consumer's Euler equation yields the dynamic IS equation in terms of the potential output gap (equation (2)), where the potential real interest rate is given by

$$
r_{t}^{p} \equiv \rho+\sigma E_{t}\left\{\Delta y_{t+1}^{p}\right\}
$$

\section{Natural Output}

Using (30), and as under flexible prices real marginal cost is given by $m c_{t}=-\varphi_{t},{ }^{18}$ the flexible-price output, natural output, $y_{t}^{f}$, satisfies

$$
-\varphi_{t}=\left(\sigma+\frac{\eta+\alpha}{1-\alpha}\right) y_{t}^{f}-\frac{1+\eta}{1-\alpha} a_{t}-\log (1-\alpha)-\xi_{t} .
$$

Thus, natural output is given by

$$
y_{t}^{f}=\psi_{y a}^{p} a_{t}-\psi_{y \varphi}^{p} \varphi_{t}+\psi_{y \varphi}^{p} \varepsilon_{t}^{c}+\vartheta_{y}^{p},
$$

where $\psi_{y a}^{p} \equiv \frac{1+\eta}{\sigma(1-\alpha)+\eta+\alpha}, \psi_{y \varphi}^{p} \equiv \frac{1-\alpha}{\sigma(1-\alpha)+\eta+\alpha}$, and $\vartheta_{y}^{p} \equiv$ $\frac{(1-\alpha) \log (1-\alpha)}{\sigma(1-\alpha)+\eta+\alpha}$. 


\section{Efficient Output and Efficient Real Interest Rate}

We follow Blanchard and Galí (2007) and Sala, Söderström, and Trigari (2010) and define efficient output as output that would prevail in perfect competition and a flexible-price economy, that is, output in an economy with no distortions - neither nominal nor real. Hence, the efficient output is the relevant notion for welfare analysis. The efficient output is derived as follows.

The maximization problem of a competitive firm is given by

$$
M \underset{Y_{t}, N_{t}}{A} X\left\{P_{t} Y_{t}-W_{t} N_{t}\right\}
$$

subject to the production function (18).

The standard first-order condition implies that the firm sets its production such that real wage equals marginal product of labor:

$$
\frac{W_{t}}{P_{t}}=(1-\alpha) A_{t} N_{t}^{-\alpha} \Rightarrow w_{t}-p_{t}=\log (1-\alpha)+a_{t}-\alpha n_{t} .
$$

Combining (37) and (15), and using aggregate production function to express labor in terms of output and technology, the efficient output is given by (in log terms)

$$
y_{t}^{e}=\psi_{y a}^{p} a_{t}+\psi_{y \varphi}^{p} \xi_{t}+\vartheta_{y}^{p} .
$$

Note that the gap between efficient output and potential output is given by

$$
y_{t}^{e}-y_{t}^{p}=\psi_{y \varphi}^{p} \varphi=\frac{1-\alpha}{\sigma(1-\alpha)+\eta+\alpha} \varphi .
$$

As $\psi_{y \varphi}^{p}>0$ and $\varphi \equiv \log (\Phi)>0$ where $\Phi>1$, when firms have monopolistic power, efficient output is higher than potential output by a constant term, which is a function of the real distortion in the economy resulting from the monopolistic power of the firms. In perfect competition, both potential and efficient outputs equal each other.

Next, we will find the relation between the potential output gap and the efficient output gap. Note that

$$
\tilde{y}_{t} \equiv y_{t}-y_{t}^{p} .
$$


As output equals potential output in the steady state, we get

$$
\tilde{y}_{t}=y_{t}-y_{t}^{e}+y_{t}^{e}-y_{t}^{p}=\left(y_{t}-y_{t}^{e}\right)-\left(y-y^{e}\right)+\left(y_{t}^{e}-y_{t}^{p}\right)-\left(y^{e}-y^{p}\right) .
$$

Defining the efficient output gap as

$$
x_{t} \equiv y_{t}-y_{t}^{e},
$$

and as the gap between efficient and potential output is constant (39), the last two terms in (41) cancel each other and $\tilde{y}_{t}=\hat{x}_{t}$. Hence, the NKPC in terms of log-deviation of the efficient output gap from its steady state is given by

$$
\pi_{t}=\beta E_{t}\left\{\pi_{t+1}\right\}+\kappa \hat{x}_{t}+\lambda \hat{\varphi}_{t} .
$$

Using the consumer's Euler equation (17), the dynamic IS equation in terms of log-deviation of efficient output gap from its steady state is given by

$$
\hat{x}_{t}=E_{t}\left(\hat{x}_{t+1}\right)-\frac{1}{\sigma}\left(i_{t}-E_{t}\left(\pi_{t+1}\right)-r_{t}^{e}\right)+\frac{1}{\sigma}\left(1-\rho^{c}\right) \xi_{t},
$$

where the efficient real interest rate is given by

$$
r_{t}^{e} \equiv \rho+\sigma E_{t}\left\{\Delta y_{t+1}^{e}\right\}=\rho+\sigma \psi_{y a}^{p} E_{t}\left\{\Delta a_{t+1}\right\}+\sigma \psi_{y \varphi}^{p} E_{t}\left\{\Delta \xi_{t+1}\right\} .
$$

Hence, the gap between efficient output and flexible-price output is

$$
y_{t}^{e}-y_{t}^{f}=\psi_{y \varphi}^{p} \varphi_{t}=\frac{1-\alpha}{\sigma(1-\alpha)+\eta+\alpha} \varphi_{t} .
$$

\section{Appendix 2. The Model's Log-linear Main Equations}

NKPC - Inflation Equation:

$$
\pi_{t}=\beta E_{t}\left\{\pi_{t+1}\right\}+\kappa \hat{x}_{t}+\lambda \hat{\varphi}_{t} .
$$

Dynamic IS Equation:

$$
\hat{x}_{t}=E_{t}\left(\hat{x}_{t+1}\right)-\frac{1}{\sigma}\left(i_{t}-E_{t}\left(\pi_{t+1}\right)-r_{t}^{e}\right)+\frac{1}{\sigma}\left(1-\rho^{\xi}\right) \xi_{t} .
$$


Monetary Policy Taylor Rule:

$$
i_{t}=\rho+\mu_{\pi} \cdot \pi_{t}+\mu_{x} \cdot g a p_{t} .
$$

Potential Output:

$$
y_{t}^{p}=\psi_{y a}^{p} a_{t}-\psi_{y \varphi}^{p} \varphi+\psi_{y \varphi}^{p} \xi_{t}+\vartheta_{y}^{p},
$$

where $\psi_{y a}^{p} \equiv \frac{1+\eta}{\sigma(1-\alpha)+\eta+\alpha}, \quad \psi_{y \varphi}^{p} \equiv \frac{1-\alpha}{\sigma(1-\alpha)+\eta+\alpha}$, and $\vartheta_{y}^{p} \equiv$ $\frac{(1-\alpha) \log (1-\alpha)}{\sigma(1-\alpha)+\eta+\alpha}$.

Potential Interest Rate:

$$
r_{t}^{p} \equiv \rho+\sigma E_{t}\left\{\Delta y_{t+1}^{p}\right\}=\rho+\sigma \psi_{y a}^{p} E_{t}\left\{\Delta a_{t+1}\right\} .
$$

Efficient Output:

$$
y_{t}^{e}=\psi_{y a}^{p} a_{t}+\psi_{y \varphi}^{p} \xi_{t}+\vartheta_{y}^{p} .
$$

Efficient Interest Rate:

$$
r_{t}^{e} \equiv \rho+\sigma E_{t}\left\{\Delta y_{t+1}^{e}\right\}=\rho+\sigma \psi_{y a}^{p} E_{t}\left\{\Delta a_{t+1}\right\}+\sigma \psi_{y \varphi}^{p} E_{t}\left\{\Delta \xi_{t+1}\right\} .
$$

Natural Output - Flexible-Price Output:

$$
y_{t}^{f}=\psi_{y a}^{p} a_{t}-\psi_{y \varphi}^{p} \varphi_{t}+\psi_{y \varphi}^{p} \xi_{t}+\vartheta_{y}^{p} .
$$

\section{Appendix 3. Calculation of Model-Based Hodrick-Prescott-Filtered Output and Linearly Detrended Output which Enter the Taylor Rules}

Hodrick-Prescott-Filtered Output Trend

The Hodrick-Prescott filter (HP filter) derives a smoothed series, $\tau_{t}$, of an $s_{t}$ series by minimizing the sum of the squared difference between the two series and a penalty term related to the smoothed degree of the smoothed series. Formally,

$$
M \underset{s_{t}}{\operatorname{in}} n \sum_{t=1}^{T}\left(s_{t}-\tau_{t}\right)^{2}+\lambda^{H P} \sum_{t=2}^{T-1}\left(\left(\tau_{t+1}-\tau_{t}\right)-\left(\tau_{t}-\tau_{t-1}\right)\right)^{2},
$$


where $\lambda^{H P}$ sets the smoothness degree. For quarterly data, $\lambda^{H P}$ is usually set to 1,600 .

First-order conditions can be expressed in matrix form as

$$
\tau=\left(\lambda^{H P} F+I\right)^{-1} s,
$$

where $I$ is a $T \times T$ identity matrix and $F$ is a $T \times T$ matrix given by

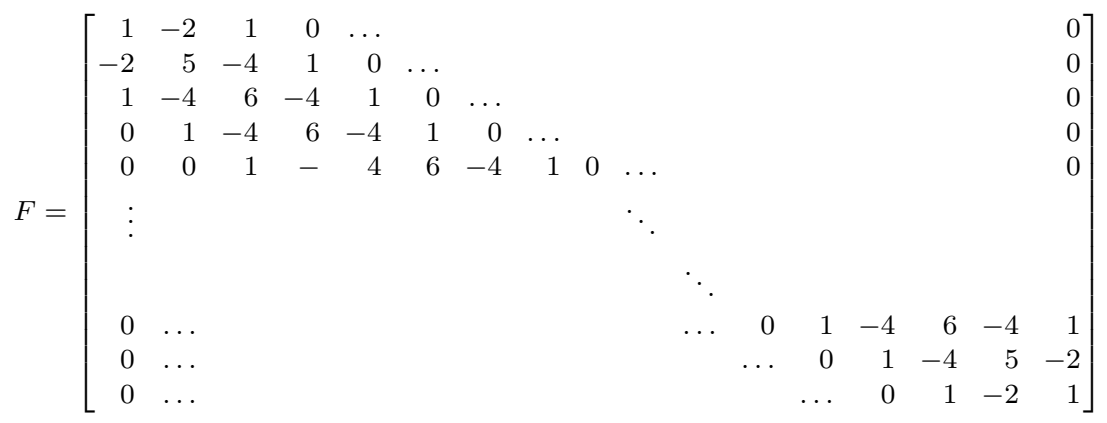

The Taylor rule used in the model responds to the endpoint output gap estimate. Therefore, the output HP-filtered trend which constructs the output gap the $\mathrm{CB}$ responds to is calculated as

$$
\tau_{T}=(\text { last line of matrix } H) \cdot s \text {, where } H=\left(\lambda^{H P} F+I\right)^{-1} \text {. }
$$

We calculate the trend using last forty observations (ten years) of simulated output.

\section{Linear Output Trend}

The linear trend of output is calculated by regressing the output series on a constant and a time trend index, that is, $\chi_{i}=$ $\left(Z^{\prime} Z\right)^{-1} Z^{\prime} y$, where $Z^{\prime} \equiv\left[\begin{array}{ccccc}1 & 1 & \ldots & & 1 \\ 0 & 1 & 2 & \ldots & T-1\end{array}\right]$, and the linear trend is given by $\chi_{i} \cdot Z^{\prime}$. Alternatively, the linear trend of output can also be calculated as a special case of the HP-filtered trend, by setting $\lambda^{H P}=\infty$. For practicality, we set $\lambda^{H P}=10^{9}$. 


\section{References}

Adolfson, M., S. Laseen, J. Linde, and L. E. Svensson. 2014. "Monetary Policy Trade-Offs in an Estimated Open-Economy DSGE Model." Journal of Economic Dynamics and Control 42: 33-49. Aoki, K. 2003. "On the Optimal Monetary Policy Response to Noisy Indicators." Journal of Monetary Economics 50 (3): 501-23.

Argov, E., A. Barnea, A. Binyamini, E. Borenstein, D. Elkayam, and I. Rozenshtrom. 2012. "MOISE: A DSGE Model for the Israeli Economy." Discussion Paper No. 2012.06, Bank of Israel.

Baxter, M., and R. G. King. 1999. "Measuring Business Cycles: Approximate Band-Pass Filters for Economic Time Series." Review of Economics and Statistics 81 (4): 575-93.

Blanchard, O., and J. Galí. 2007. "Real Wage Rigidities and the New Keynesian Model." Journal of Money, Credit and Banking 39 (s1): $35-65$.

Christiano, L. J., and T. J. Fitzgerald. 2003. "The Band Pass Filter." International Economic Review 44 (2): 435-65.

Christoffel, K., G. Coenen, and A. Warne. 2008. "The New AreaWide Model of the Euro Area: A Micro-Founded Open-Economy Model for Forecasting and Policy Analysis." ECB Working Paper No. 944.

Clarida, R., J. Galí, and M. Gertler. 1999. "The Science of Monetary Policy: A New Keynesian Perspective." Journal of Economic Literature 37 (4): 1661-1707.

Coenen, G., F. Smets, and I. Vetlov. 2008. "Estimation of Euro Area Output Gap Using the NAWM." Working Paper No. 5/2009, Bank of Lithuania.

Cúrdia, V., A. Ferrero, G. C. Ng, and A. Tambalotti. 2015. "Has U.S. Monetary Policy Tracked the Efficient Interest Rate?" Journal of Monetary Economics 70: 72-83.

Galí, J. 2008. Monetary Policy, Inflation, and the Business Cycle: An Introduction to the New Keynesian Framework. Princeton, NJ: Princeton University Press.

Harvey, A. C., and A. Jaeger. 1993. "Detrending, Stylized Facts and the Business Cycle." Journal of Applied Econometrics 8 (3): $231-47$. 
Justiniano, A., and G. E. Primiceri. 2008. "Potential and Natural Output." Unpublished manuscript, Federal Reserve Bank of Chicago.

McCallum, B. T. 2001. "Should Monetary Policy Respond Strongly to Output Gaps?" American Economic Review: Papers and Proceedings 91 (2): 258-62.

Neiss, K. S., and E. Nelson. 2005. "Inflation Dynamics, Marginal Costs, and the Output Gap: Evidence from Three Countries." Journal of Money, Credit and Banking 37 (6, December): $1019-45$.

Orphanides, A. 2003. "Monetary Policy Evaluation with Noisy Information." Journal of Monetary Economics 50 (3): 605-31.

Orphanides, A., R. D. Porter, D. Reifschneider, R. Tetlow, and F. Finan. 2000. "Errors in the Measurement of the Output Gap and the Design of Monetary Policy." Journal of Economics and Business 52 (1-2): 117-41.

Rabanal, P., and J. F. Rubio-Ramírez. 2008. "Comparing New Keynesian Models in the Euro Area: A Bayesian Approach." Spanish Economic Review 10 (1): 23-40.

Rotemberg, J. J., and M. Woodford. 1997. "An Optimization-Based Econometric Framework for the Evaluation of Monetary Policy." NBER Macroeconomics Annual 199\%, ed. B. S. Bernanke and J. Rotemberg, 297-361. MIT Press.

Sala, L., U. Söderström, and A. Trigari. 2010. "The Output Gap, the Labor Wedge, and the Dynamic Behavior of Hours." CEPR Discussion Paper No. 8005.

Smets, F. 2002. "Output Gap Uncertainty: Does It Matter for the Taylor Rule?" Empirical Economics 27 (1): 113-29.

Smets, F., and R. Wouters. 2003a. "An Estimated Stochastic Dynamic General Equilibrium Model of the Euro Area." Journal of the European Economic Association 1 (5): 1123-75. . 2003b. "Output Gaps: Theory versus Practice." Paper presented at the 9th International Conference of the Society for Computational Economics, Seattle, Washington, July 10-13.

Svensson, L. E., and M. Woodford. 2004. "Indicator Variables for Optimal Policy under Asymmetric Information." Journal of Economic Dynamics and Control 28 (4): 661-90. 
Taylor, J. B. 1993. "Discretion versus Policy Rules in Practice." Carnegie Rochester Conference Series on Public Policy 39 (1): 195-214.

_. 1999. "A Historical Analysis of Monetary Policy Rules." In Monetary Policy Rules, ed. J. B. Taylor, 319-48. University of Chicago Press.

Woodford, M. 2003. Interest and Prices: Foundations of a Theory of Monetary Policy. Princeton, NJ: Princeton University Press. 